Antarctic Science 27(6), 598-616 (2015) (C) Antarctic Science Ltd 2015. This is an Open Access article, distributed under the terms of the Creative Commons Attribution licence (http://creativecommons.org/licenses/by/4.0/), which permits unrestricted re-use, distribution, and reproduction in any medium, provided the original work is properly cited.

\title{
Review of tropospheric temperature, absolute humidity and integrated water vapour from the HAMSTRAD radiometer installed at Dome C, Antarctica, 2009-14
}

\author{
P. RICAUD ${ }^{1}$, P. GRIGIONI ${ }^{2}$, R. ZBINDEN ${ }^{1}$, J.-L. ATTIÉÉ, ${ }^{1,3}$, L. GENONI ${ }^{4}$, A. GALEANDRO ${ }^{5}$, L. MOGGIO ${ }^{6}$, \\ S. MONTAGUTI ${ }^{6}$, I. PETENKO ${ }^{7,8}$ and P. LEGOVINI ${ }^{7}$ \\ ${ }^{1}$ Météo-France/Centre National de la Recherche Scientifique, Toulouse, France \\ ${ }^{2}$ ENEA, Roma, Italy \\ ${ }^{3}$ Laboratoire d'Aérologie, Toulouse, France \\ ${ }^{4}$ Trieste University, Trieste, Italy \\ ${ }^{5}$ Politecnico di Bari, Bari, Italy \\ ${ }^{6}$ Institute of Atmospheric Sciences and Climate, Bologna, Italy \\ ${ }^{7}$ Institute of Atmospheric Sciences and Climate, Roma, Italy \\ ${ }^{8}$ Obukhov Institute of Atmospheric Physics, Moscow, Russia \\ philippe.ricaud@meteo.fr
}

\begin{abstract}
The HAMSTRAD ( $\mathrm{H}_{2} \mathrm{O}$ Antarctica Microwave Stratospheric and Tropospheric Radiometers) instrument is a microwave radiometer installed at Dome C (Antarctica, $75^{\circ} 06^{\prime} \mathrm{S}, 123^{\circ} 21^{\prime} \mathrm{E}, 3233 \mathrm{~m}$ a.m.s.1.) dedicated to the tropospheric measurements of temperature, absolute humidity and integrated water vapour (IWV). The aim of the present paper is to review the entire HAMSTRAD dataset from 2009 to 2014 with a 7-minute integration time from 0 to $10 \mathrm{~km}$ by comparison with coincident radiosondes launched at $12 \mathrm{~h} 00$ UTC at Dome C. Based upon an extensive evaluation of biases and time correlation coefficients $(r)$, we can state: i) IWV is of excellent quality $(r>0.98)$ and can be used without retrieving significant bias, ii) temperature is suitable for scientific analyses over $0-10 \mathrm{~km}$ with a high time correlation with radiosondes $(r>0.80)$ and iii) absolute humidity is suitable for scientific analyses over $0-4 \mathrm{~km}$ with a moderate time correlation against radiosondes $(r>0.70)$. The vertical distribution of temperature $(0-10 \mathrm{~km})$ and absolute humidity $(0-4 \mathrm{~km})$ is subject to biases that need to be removed if the analyses require the use of vertical profiling. The HAMSTRAD dataset is provided in open access to the scientific community.
\end{abstract}

Received 31 March 2015, accepted 28 May 2015, first published online 30 July 2015

Key words: ground-based microwave radiometer, polar atmosphere, radiosonde, statistical analyses, troposphere

\section{Introduction}

Water vapour $\left(\mathrm{H}_{2} \mathrm{O}\right)$ is the main greenhouse gas emitting and absorbing infrared radiation. Its changes directly impact on the radiative balance of the Earth, affecting climate evolution (Solomon et al. 2010). At global scale, the $\mathrm{H}_{2} \mathrm{O}$ long-term variability both in the troposphere and stratosphere is still an enigma or, at least, under discussion. Indeed, neither the positive trend in methane (stratospheric source of $\mathrm{H}_{2} \mathrm{O}$ ) nor the negative trend of the tropopause temperature (direct injection of $\mathrm{H}_{2} \mathrm{O}$ from the troposphere to the stratosphere) can explain the positive trend in stratospheric $\mathrm{H}_{2} \mathrm{O}$ measured by balloon-borne instruments up to 2000 and the negative trend observed since (Scherer et al. 2008). However, in the upper troposphere-lower stratosphere, climate models have been able to reproduce the evolution of $\mathrm{H}_{2} \mathrm{O}$ as measured by spaceborne instruments (Hegglin et al. 2014).
At polar latitudes, the extreme conditions encountered increase the sensitivity to global warming and the speed of the temperature variations in response compared to mid-latitudes (Turner et al. 2006). For example, the warming of the Antarctic winter troposphere is greater than anywhere else on Earth with a rate of $0.5-0.7 \mathrm{~K}$ per decade. However, the physical processes which rule the polar climate are still misunderstood and poorly represented in models (Hines et al. 2004).

The Antarctic Plateau is one of the coldest and driest places in the world (e.g. Hagelin et al. 2008). The Dome C station (Concordia Station) in Antarctica $\left(75^{\circ} 06^{\prime} \mathrm{S}, 123^{\circ} 21^{\prime} \mathrm{E}\right.$, $3233 \mathrm{~m}$ a.m.s.1.) is a unique site with the opportunity to actually test the quality of the measurements (Aristidi et al. 2003, Aumann et al. 2006, de Gregori et al. 2012) and meteorological analyses (Genthon et al. 2010). Its location is geographically representative of the eastern Antarctic Plateau (average altitude $2500 \mathrm{~m}$ a.s.1.), and 
consequently, can be considered as less affected by local phenomena, such as orographic waves, katabatic winds, oceanic breeze, etc., that are far more prominent at coastal stations. Several studies have already shown the extreme difficulty of modelling and analysis (assimilation of measurements into models) to represent the time evolution of the Antarctic atmosphere as measured by different sensors at different time scales (diurnal cycle, e.g. Genthon et al. 2010, annual evolution, e.g. Tomasi et al. 2012, and intra-seasonal variability, e.g. Argentini et al. 2007), and different vertical layers (planetary boundary layer, e.g. Argentini et al. 2013, free troposphere and upper troposphere-lower stratosphere, e.g. Ricaud et al. 2014c).

For simplicity, because the Dome $\mathrm{C}$ station is at high altitude, from now on 'altitude' will always refer to an altitude above the surface. The HAMSTRAD $\left(\mathrm{H}_{2} \mathrm{O}\right.$ Antarctica Microwave Stratospheric and Tropospheric Radiometers) radiometer has been presented in detail in Ricaud et al. 2010b. It is a state-of-the-art microwave radiometer dedicated to the tropospheric measurement of absolute humidity at $169-197 \mathrm{GHz}$ (G-band, strong $\mathrm{H}_{2} \mathrm{O}$ line at $183.3 \mathrm{GHz}$ ), together with temperature from the oxygen $\left(\mathrm{O}_{2}\right)$ line $(51-59 \mathrm{GHz}, \mathrm{V}$-band, lower frequency wing of the $\mathrm{O}_{2}$ line), in very cold and dry environments, such as encountered at Dome $\mathrm{C}$ all year round. The instrument was installed at Dome C in January 2009 and, except for a few periods that will be detailed later, has been operational since January 2010. As reported in Ricaud et al. (2010b, 2014c), the HAMSTRAD radiometer has routinely sampled the whole 24-hour diurnal cycle with a 7-minute integration time from 2009 to 2014, and from 0 to $10 \mathrm{~km}$. Although the top of the planetary boundary layer (PBL) decreases on average from $\sim 200 \mathrm{~m}$ in summer to $\sim 30 \mathrm{~m}$ in winter (Ricaud et al. 2012), for this analysis we set the PBL to $200 \mathrm{~m}$ from the surface. Nevertheless, in summer, the PBL top height is extremely variable ranging from $\sim 100$ to $\sim 800 \mathrm{~m}$ within a few days (Ricaud et al. 2012). The free troposphere is defined as $200 \mathrm{~m}$ to $6 \mathrm{~km}$, and the upper troposphere-lower stratosphere as $6-10 \mathrm{~km}$. The vertical resolution for both absolute humidity and temperature measurements is $\sim 20-50 \mathrm{~m}$ in the PBL, $\sim 100 \mathrm{~m}$ in the free troposphere and $\sim 500 \mathrm{~m}$ in the upper troposphere-lower stratosphere (Ricaud et al. 2013).

In Ricaud et al. (2010a, 2012, 2013, 2014a, 2014b, 2014c), by considering the HAMSTRAD measurements performed in 2009 and 2010 and in other datasets, e.g. in situ, radiosondes, satellite, lidar, meteorological analyses, back-trajectories, mesoscale models, we have already studied the strengths and weaknesses of this instrument by calculating biases and correlations. We have also investigated the different processes occurring in the Antarctic troposphere: i) Diurnal variability of temperature and absolute humidity in the PBL. ii) Seasonal variability of temperature and absolute humidity in the PBL and in the free troposphere linked
Table I. Time evolution of the major changes in the HAMSTRAD measurements and acquisition versions.

\begin{tabular}{|c|c|c|}
\hline Date & Version & Major changes \\
\hline 22 January 2009 & V7.51 & $\begin{array}{l}\text { Beginning of the summer campaign at } \\
\text { Dome C } \\
\text { - First HAMSTRAD measurements } \\
\text { - Outdoor measurements } \\
\text { - Blue foam }\end{array}$ \\
\hline 27 January 2009 & & Blue foam replaced by white foam \\
\hline 2 February 2009 & & End of the summer campaign \\
\hline 8 January 2010 & & Beginning of the outdoor measurements \\
\hline 16 January 2010 & & Beginning of the indoor measurements \\
\hline 26 May 2011 & & $\begin{array}{l}\text { Failure of the } 183-\mathrm{GHz} \text { noise diode } \\
\text { - HAMSTRAD stops measuring }\end{array}$ \\
\hline 9 February 2012 & & $\begin{array}{l}\text { Replacement of the } 183-\mathrm{GHz} \text { noise diode } \\
\text { - HAMSTRAD starts measuring again }\end{array}$ \\
\hline 13 January 2013 & V8.31 & $\begin{array}{l}\text { More scanning angles compared to V7.51 } \\
\text { New retrievals including the liquid water } \\
\text { path }\end{array}$ \\
\hline 14 February 2014 & V8.46 & More reliable than V8.31 \\
\hline
\end{tabular}

to the origin of air masses (dry and cold periods associated with Antarctic origin of air masses whilst less dry and less cold periods associated with oceanic origin of air masses). iii) Temperature versus absolute humidity correlation along the vertical from the lowermost to the middle troposphere. Finally, iv) episodes of clouds and diamond dusts above the station.

Up to now, only the HAMSTRAD measurements performed during 2009-10 have been analysed. The aim of this paper is, firstly, to present the entire record of the HAMSTRAD measurements of tropospheric temperature and absolute humidity together with integrated water vapour (IWV) performed routinely over a six year period (2009-14) since it was deployed at the Dome C station. We will highlight the major changes that have occurred during the six year period both regarding the hardware and the software, and the availability of data depending on the years considered. Secondly, we will quantify the biases of HAMSTRAD measurements against radiosondes launched on a daily basis at Dome $\mathrm{C}$ over the same six year period, and we will highlight the temporal correlation with the radiosonde datasets by calculating linear Pearson correlation coefficients $(r)$. Our six year period results will then be compared with the previous extensive 2009-10 results. Finally, we will propose the debiased temperature and absolute humidity tropospheric vertical profiles derived from the raw HAMSTRAD dataset.

\section{Datasets}

\section{HAMSTRAD}

The HAMSTRAD radiometer has been presented in detail in Ricaud et al. (2010b, 2014b). The goal of the 
instrument is to sound the troposphere in very cold and dry environments to obtain temperature and absolute humidity profiles, with IWV calculated from the retrieved water vapour profile integrated from the surface to $10 \mathrm{~km}$. The instrument requires a liquid nitrogen calibration once or twice per year.

After an initial campaign in February-June 2008 at high altitude (cold and dry environment) in Europe at the Pic du Midi Station $\left(42^{\circ} 56^{\prime} \mathrm{N}, 0^{\circ} 08^{\prime} \mathrm{E}, 2877 \mathrm{~m}\right.$ a.m.s.l., France) to validate the water vapour measurements (Ricaud et al. 2010a), the radiometer was sent to Dome C. Table I shows the history of the operation of HAMSTRAD at Dome C from January 2009 to December 2014. The very first measurements of HAMSTRAD were collected on 22 January 2009, using the acquisition software V7.51 (Ricaud et al. 2013) following deployment outdoors using a blue foam to cover the instrument that was not designed for the $183-\mathrm{GHz} \mathrm{H}_{2} \mathrm{O}$ line but rather for the $22-\mathrm{GHz} \mathrm{H}_{2} \mathrm{O}$ line. (For a description of the foams used by the radiometers developed by the RPG company at different frequencies and their associated optical performances see http://www.radiometer-physics.de/rpg/html/Products_ Radiometers_Profilers.html.) On 27 January 2009, the white foam adapted for the $183-\mathrm{GHz} \mathrm{H}_{2} \mathrm{O}$ line was installed. The 2009 summer campaign ended on 2 February 2009. In 2010, the summer campaign started on 8 January with an outdoor installation. Few days later, the shelter dedicated to HAMSTRAD was completed allowing the first indoor measurements from HAMSTRAD on 16 January 2010. From that date, the radiometer has continuously operated in that shelter with a daily data transfer either by email and/or by ftp to France. On 26 May 2011, a major failure of the 183-GHz noise diode impacted on the internal calibration of the $\mathrm{H}_{2} \mathrm{O}$ spectra and prevented measurements of absolute humidity vertical profiles and IWV, and also affected the $60-\mathrm{GHz}$ receiver $\left(\mathrm{O}_{2}\right.$ line to retrieve temperature). The 183-GHz noise diode was changed on 9 February 2012 and HAMSTRAD was operational again, providing meaningful measurements of temperature and absolute humidity vertical profiles together with IWV. Consequently, temperature vertical profiles from 26 May 2011 to 9 February 2012 should not be used for any scientific analysis and are not presented in this paper. On 13 January 2013, an updated version of the acquisition software (V8.31) was installed that used more scanning angles at low elevations (10 instead of 6) in order to achieve better precision and resolution in the PBL. Furthermore, V8.31 offered the possibility to retrieve a new parameter, namely the liquid water path, providing information on the presence of cloud above the observation site. Finally, on 14 February 2014, the latest version of the analysis software, V8.46, was installed to improve the stability of the acquisition system.
Table II. HAMSTRAD measurements over the year or over the period of measurements (in italics) from 2009 to 2014.

\begin{tabular}{llcc}
\hline Year & Period & $\begin{array}{c}\text { Number of } \\
\text { days of } \\
\text { measurements }\end{array}$ & $\begin{array}{c}\text { Percentage of } \\
\text { days over the } \\
\text { year (or the period } \\
\text { of measurements) }\end{array}$ \\
\hline 2009 & 22 January-2 February & 12 & 100 \\
2010 & 18 January-31 December & 347 & 95 \\
2011 & 1 January-26 May & 125 & 83 \\
2012 & 10 February-31 December & 299 & 82 \\
2013 & 1 January-31 December & 289 & 80 \\
2014 & 1 January-31 December & 306 & 84 \\
\hline
\end{tabular}

To calculate the vertical profiles from calibrated spectra measured by the radiometer, a statistical approach was used, performed with a linear (V7.51) or a quadratic (V8.31 and V8.46) regression based on one thousand soundings performed at the South Pole (V7.51) or at Dome C (V8.31 and V8.46). This inversion method has the main advantage of instantly producing vertical profiles. However, it has the main drawback of being unable to generate mathematical functions (such as scanning functions generated in optimal estimation) to characterize the vertical resolution of the measurement and the contamination of the a priori information on the estimated vertical profile. Ricaud et al. (2013) showed that the linear/quadratic regression and the optimal estimation methods give consistent results with respect to the accuracy and the vertical resolution of the measurements of absolute humidity and temperature.

Table II shows the number of days and the period of measurements of the HAMSTRAD radiometer from 2009 to 2014. If data from 2009, when the instrument was deployed outdoors for 2 weeks, and from June 2011 to January 2012, when a major failure occurred, are excluded the efficiency of the HAMSTRAD radiometer to sound the atmosphere is rather elevated, greater than $80 \%$. Indeed, the number of days of measurements per year is $347(95 \%)$ in 2010, 125 (but $83 \%$ January to May) in $2011,299(82 \%)$ in $2012,289(80 \%)$ in 2013 , and $306(84 \%)$ in 2014.

A number of conclusions can be drawn from the extensive validation and scientific studies that have been performed, mainly in 2009 and 2010, to assess the quality of the measurements and to explain some physical processes from these measurements. The instrument shows a very high sensitivity in the PBL, a high sensitivity in the free troposphere and a very weak sensitivity in the upper troposphere-lower stratosphere. Firstly, considering temperature (Ricaud et al. 2014c), in the PBL, a positive bias of $2-10 \mathrm{~K}$ is observed between HAMSTRAD and some of the other datasets (radiosondes, in situ analyses, the atmospheric infrared sounder (AIRS) spaceborne sensor) (Tobin et al. 2006), while a negative bias from -1 to $-5 \mathrm{~K}$ is 


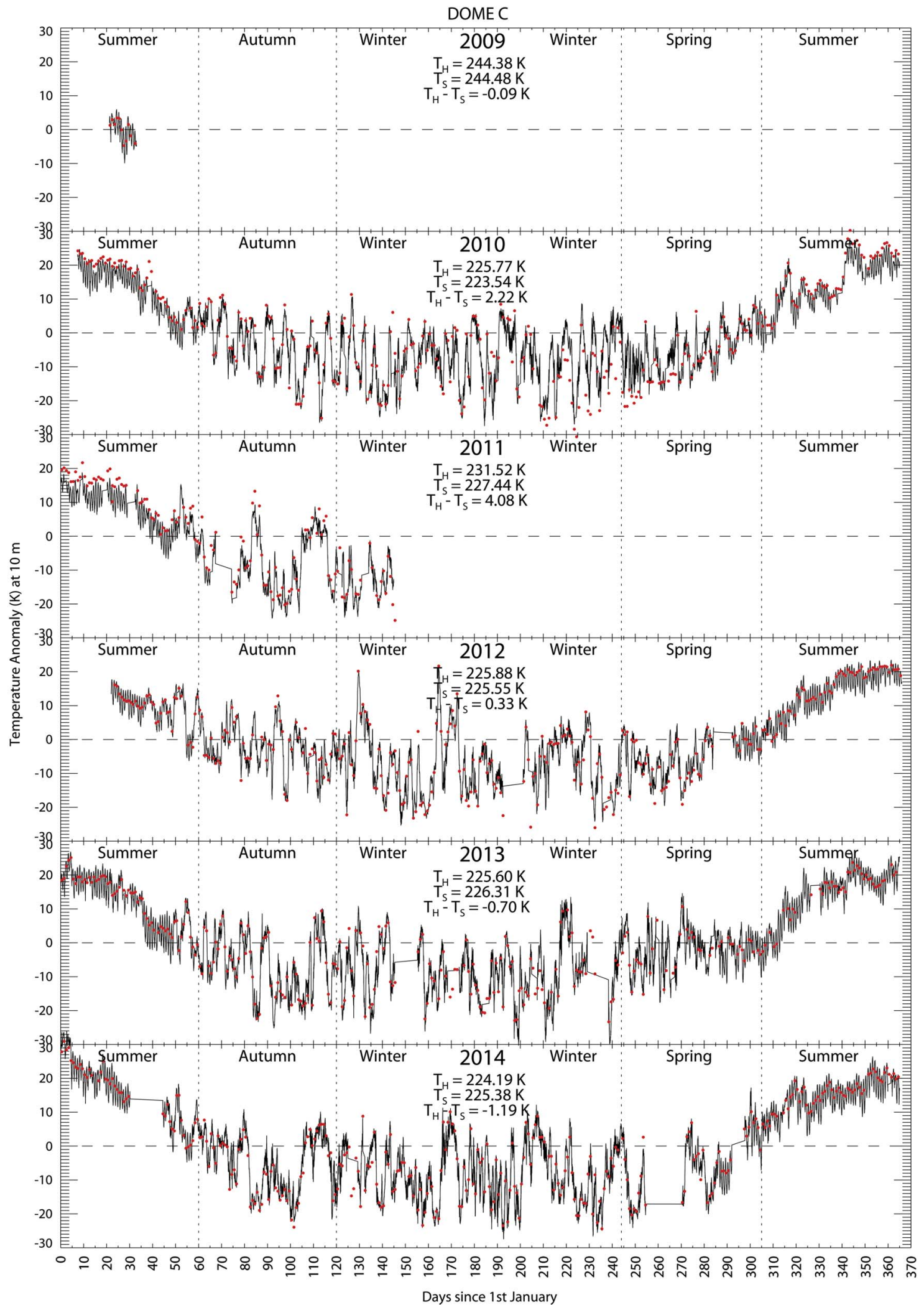

Fig. 1. Time series from 2009 to 2014 (top to bottom) of the temperature anomaly (K) at 10 m as measured by HAMSTRAD (black line) and the radiosondes (red dots). The yearly-averaged temperatures (K) from HAMSTRAD $\left(\mathrm{T}_{\mathrm{H}}\right)$ and from the radiosondes $\left(\mathrm{T}_{\mathrm{S}}\right)$ and the difference $\left(\mathrm{T}_{\mathrm{H}}-\mathrm{T}_{\mathrm{S}}\right)$ are highlighted in each panel. 


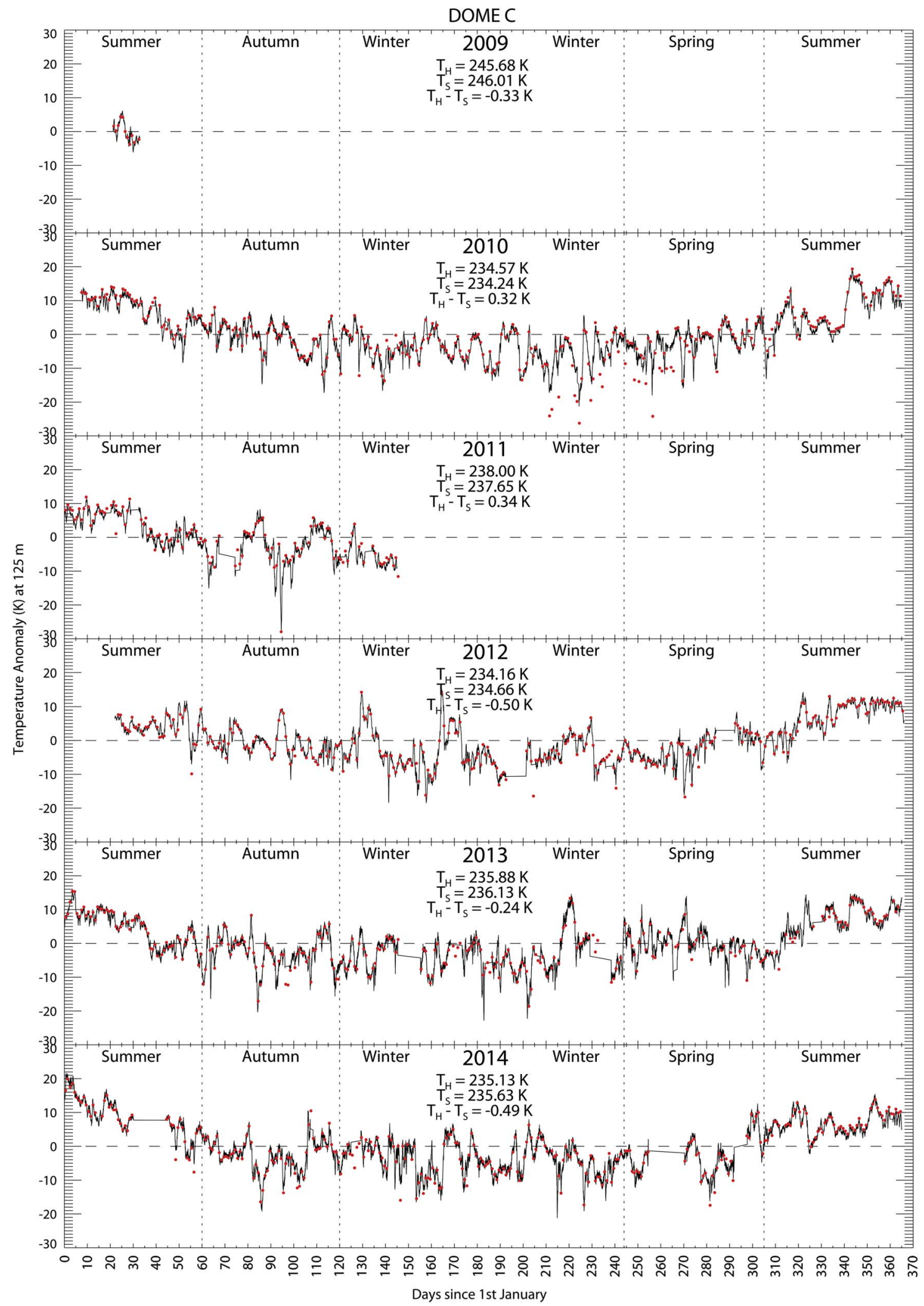

Fig. 2. Time series from 2009 to 2014 (top to bottom) of the temperature anomaly (K) at 125 m as measured by HAMSTRAD (black line) and the radiosondes (red dots). The yearly-averaged temperatures (K) from HAMSTRAD ( $\left.\mathrm{T}_{\mathrm{H}}\right)$ and from the radiosondes $\left(\mathrm{T}_{\mathrm{S}}\right)$ and the difference $\left(\mathrm{T}_{\mathrm{H}}-\mathrm{T}_{\mathrm{S}}\right)$ are highlighted in each panel. 
DOME C

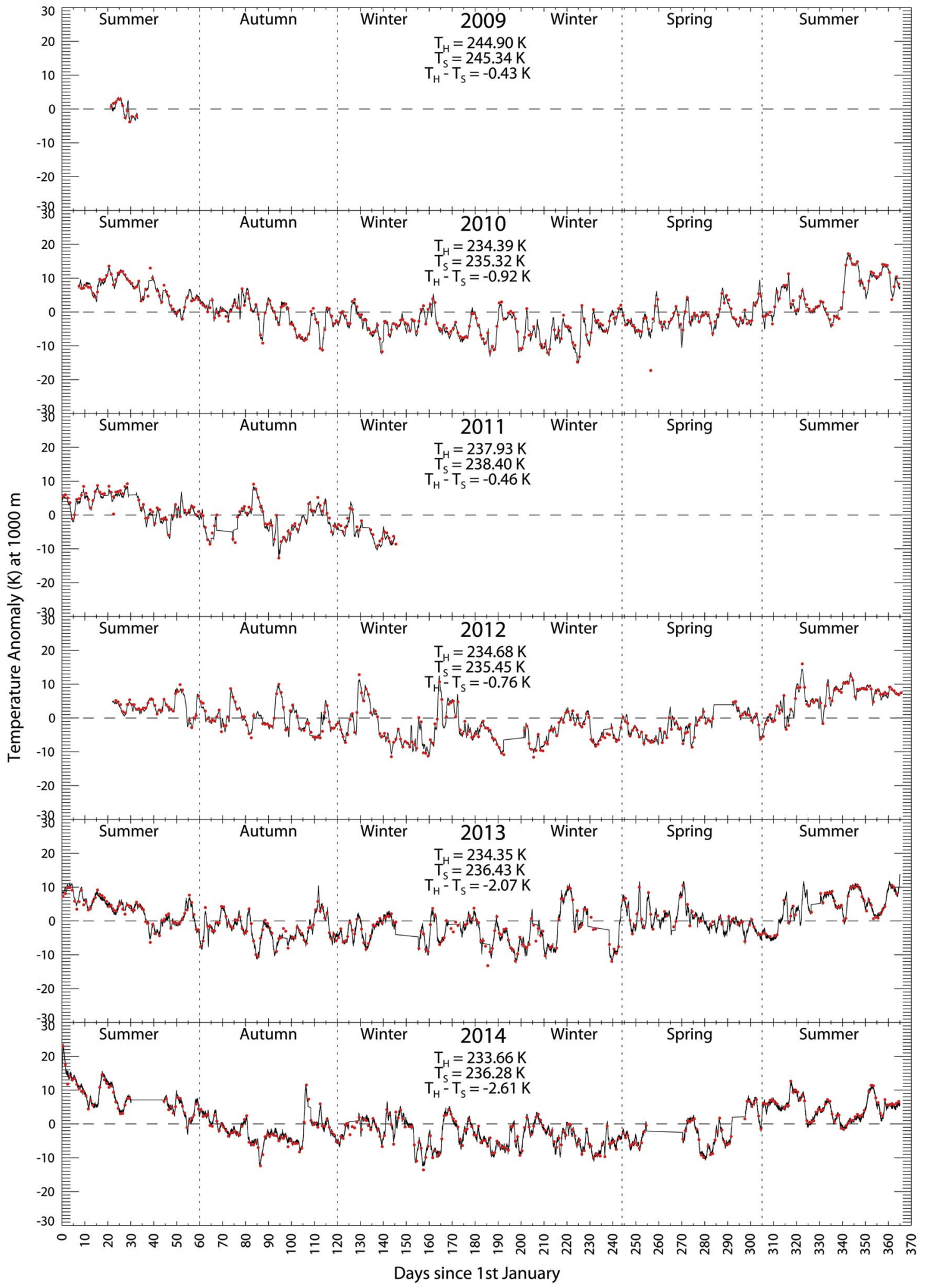

Fig. 3. Time series from 2009 to 2014 (top to bottom) of the temperature anomaly (K) at 1000 m as measured by HAMSTRAD (black line) and the radiosondes (red dots). The yearly-averaged temperatures (K) from HAMSTRAD ( $\left.\mathrm{T}_{\mathrm{H}}\right)$ and from the radiosondes $\left(T_{S}\right)$ and the difference $\left(T_{H}-T_{S}\right)$ are highlighted in each panel. 
DOME C

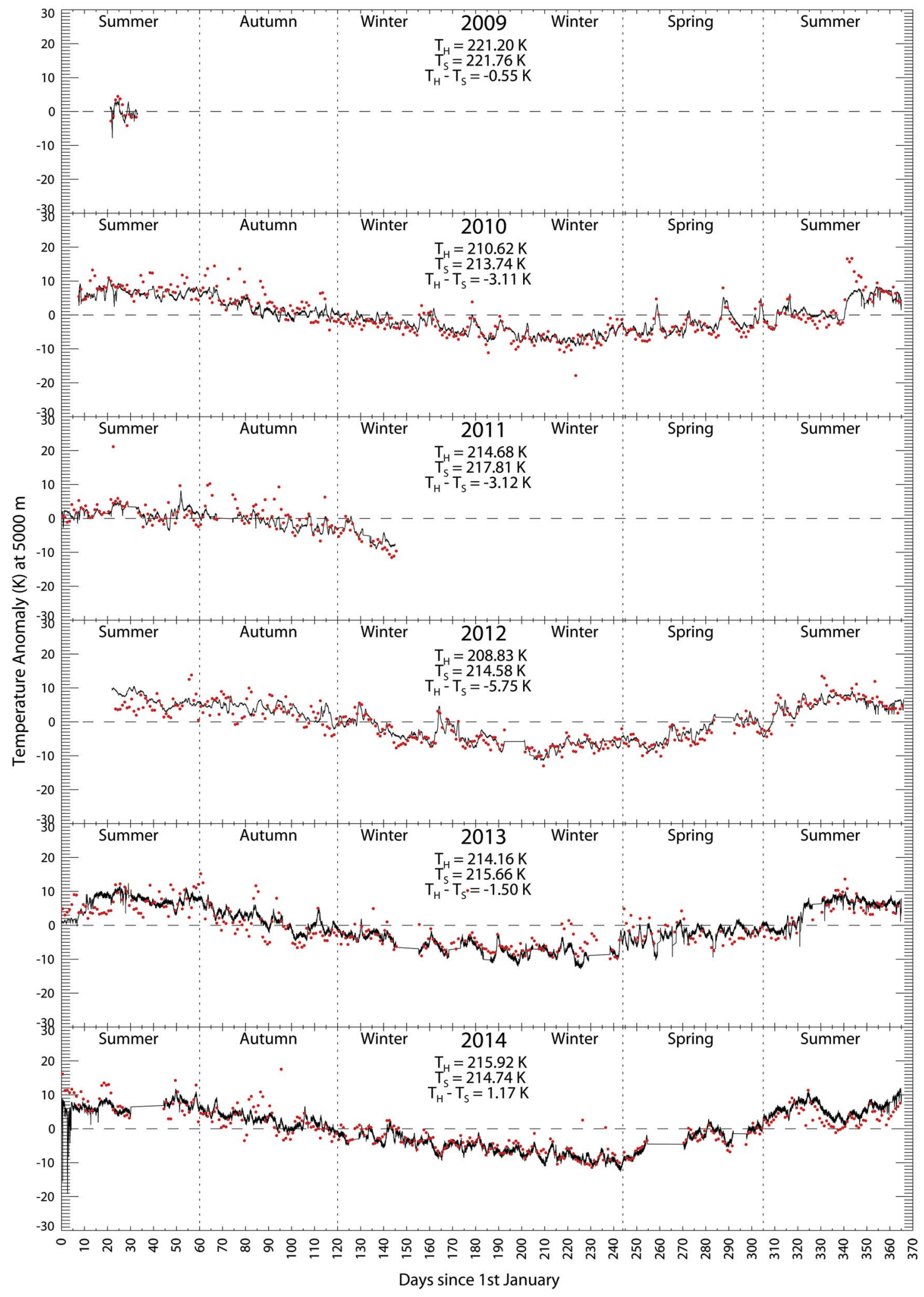

Fig. 4. Time series from 2009 to 2014 (top to bottom) of the temperature anomaly (K) at $5000 \mathrm{~m}$ as measured by HAMSTRAD (black line) and the radiosondes (red dots). The yearly-averaged temperatures $(\mathrm{K})$ from HAMSTRAD $\left(\mathrm{T}_{\mathrm{H}}\right)$ and from the radiosondes $\left(\mathrm{T}_{\mathrm{S}}\right)$ and the difference $\left(\mathrm{T}_{\mathrm{H}}-\mathrm{T}_{\mathrm{S}}\right)$ are highlighted in each panel. 
a

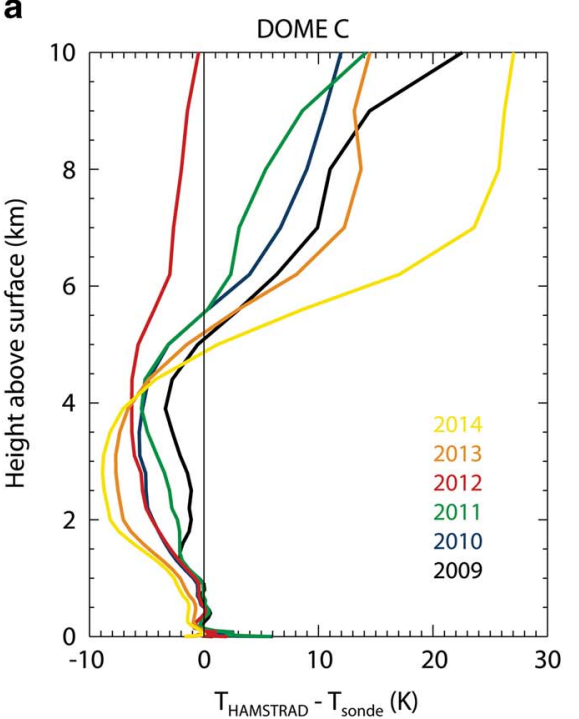

b

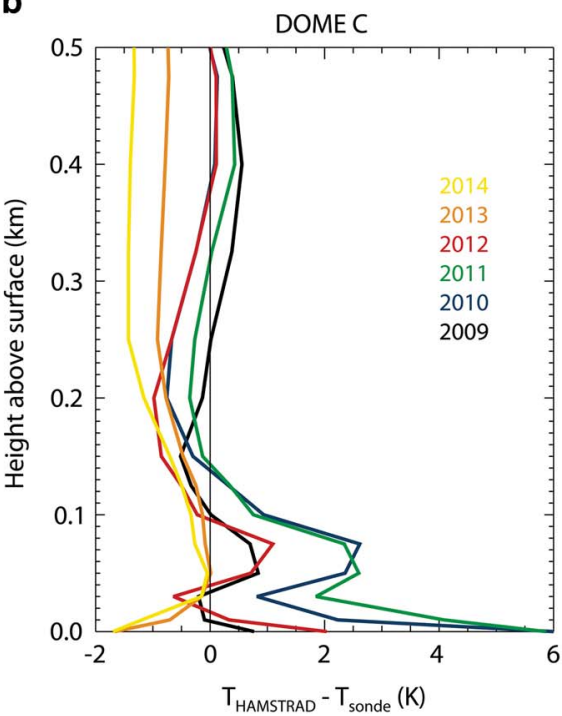

Fig. 5. Vertical distribution of the yearly-averaged biases in temperature (K) of HAMSTRAD versus radiosondes in 2009 (black line), 2010 (blue line), 2011 (green line), 2012 (red line), 2013 (orange line) and 2014 (yellow line) over the vertical ranges: a. $0-10 \mathrm{~km}$ and b. $0-500 \mathrm{~m}$. calculated between HAMSTRAD and the infrared atmospheric sounding interferometer (IASI) spaceborne sensor (Herbin et al. 2009). In the free troposphere, below $4 \mathrm{~km}$, a $1-5 \mathrm{~K}$ negative bias is detected between HAMSTRAD and all the other measurements, and a positive bias of $\sim 5-10 \mathrm{~K}$ above. Secondly, IWV is of a high quality, namely $\sim 1-2 \%$ wetter than radiosondes and spaceborne IWV measurements. Thirdly, absolute humidity profiles are wetter by $0.1-0.3 \mathrm{~g} \mathrm{~m}^{-3}$ than all the other datasets below $\sim 2 \mathrm{~km}$ and drier by $\sim 0.1 \mathrm{~g} \mathrm{~m}^{-3}$ above.

Below $\sim 6 \mathrm{~km}$, the correlation coefficients $(r)$ of the time series of HAMSTRAD measurements versus the time series of radiosonde, in situ, spaceborne data and meteorological analyses are very high $(r>0.8)$ for temperature and IWV, but are much less for absolute humidity $(r \sim 0.2-0.8)$. Based on the known biases and correlation coefficients calculated in 2009 and 2010, we have systematically analysed all of the HAMSTRAD data over the whole period of measurement at Dome C from 2009 to 2014 with a high temporal sampling of $\sim 7$ min by comparison with radiosondes launched on a daily basis from the station.

\section{Radiosondes}

The radiosonde programme at Dome $\mathrm{C}$ is presented in Ricaud et al. (2014c), together with the biases according to temperature and absolute humidity. Here we have used the temperature and humidity profiles from RS92 radiosondes using the standard Vaisala evaluation routines with no correction of time lag or sensor heating effect. We recall that some corrections performed on the
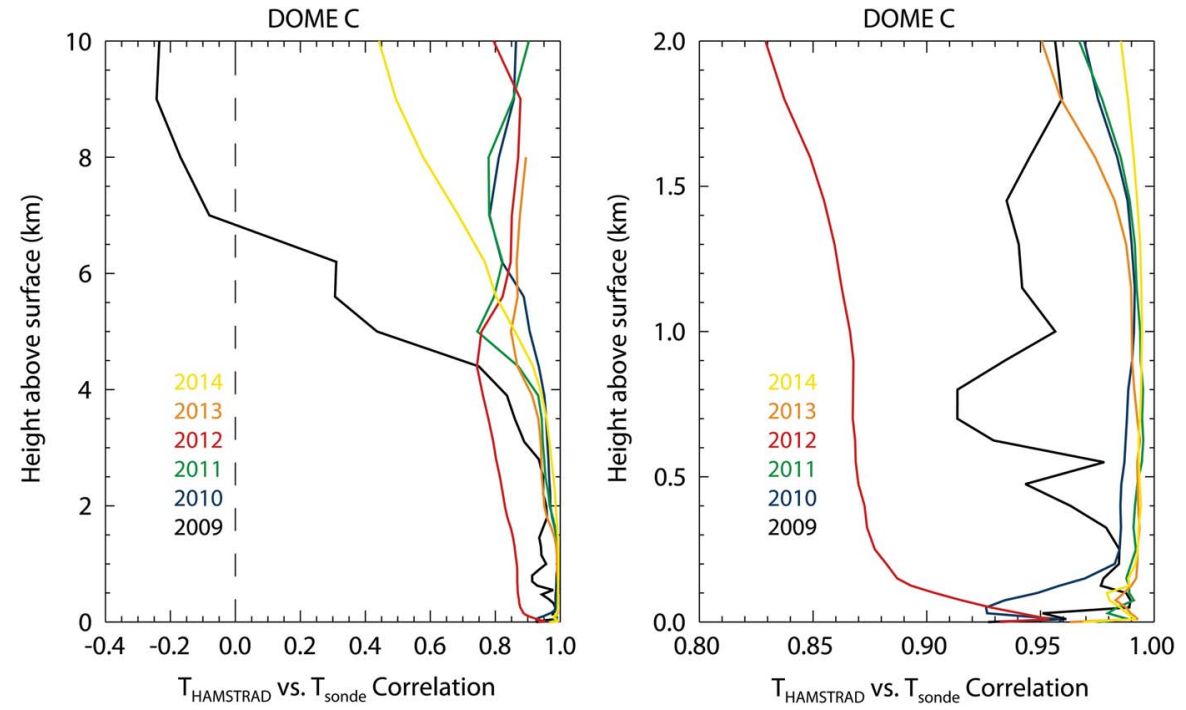

Fig. 6. Vertical distribution of the linear Pearson correlation coefficient between the time evolution of temperature as measured by HAMSTRAD and radiosondes in 2009 (black line), 2010 (blue line), 2011 (green line), 2012 (red line), 2013 (orange line) and 2014 (yellow line) over the vertical ranges: a. $0-10 \mathrm{~km}$ and b. $0-2 \mathrm{~km}$. 
2009 radiosonde data according to Miloshevich et al. (2006) exhibited a weak impact ( $+4 \%$ maximum on IWV) on the vertical profiles in the troposphere (Ricaud et al. 2013). Furthermore, using the procedure developed in Miloshevich et al. (2009), Tomasi et al. (2011, 2012) found that the corresponding correction factor for humidity provided by the radiosonde at Dome $\mathrm{C}$, for the $630-470 \mathrm{hPa}$ layer, varied between 1.10 and 1.15 for daytime and from 0.98 to 1.00 for night-time. The $630-470 \mathrm{hPa}$ pressure range corresponds to a layer between the surface and $\sim 2 \mathrm{~km}$ which mainly contributes to the calculation of IWV. Regarding temperature, a cold bias is observed in the RS92 of $1.2 \mathrm{~K}$ from the surface up to $4 \mathrm{~km}$ (Tomasi et al. 2011, 2012).

\section{Tropospheric temperature}

The time evolution of the temperature anomaly (difference between temperature and the yearly-averaged temperature) as measured by HAMSTRAD at 7-min temporal resolution and by the radiosondes at $10 \mathrm{~m}(\mathrm{PBL})$ is shown in Fig. 1 for 2009-14. The same evolution is shown in Figs $2-4$ for the temperature anomaly at $125 \mathrm{~m}$ (middle/upper PBL in summer and low free troposphere in the other seasons), $1000 \mathrm{~m}$ (free troposphere) and $5000 \mathrm{~m}$ (upper troposphere), respectively. The yearlyaveraged biases along the vertical $(0-10 \mathrm{~km})$ between HAMSTRAD and the radiosondes are shown in Fig. 5 for 2009-14. The linear Pearson correlation coefficients $(r)$ along the vertical $(0-10 \mathrm{~km})$ between HAMSTRAD and the radiosondes are shown in Fig. 6 for 2009-14. To calculate $r$ for a considered year, a coincidence time window of \pm 20 minutes has been applied to the HAMSTRAD measurements at $12 \mathrm{~h} 00$ UTC whenever a radiosonde was actually launched on a particular day. Note that, consistent with Ricaud et al. (2014c), we define the four seasons at Dome C as: summer (January, February, November and December), autumn (March and April), spring (September and October) and winter (May, June, July and August). The yearly-averaged bias is calculated only over 12 days in 2009 (22 January to 2 February) and 125 days in 2011 (1 January to 26 May) (see Table II).

First, irrespective of the altitude or the year considered (Figs 1-4), the seasonal variation in temperature anomaly is characterized by a maximum in summer and a minimum in winter, with an amplitude larger in the lowermost troposphere $( \pm 20-25 \mathrm{~K}$ at $10 \mathrm{~m})$ than in the upper troposphere $( \pm 10 \mathrm{~K}$ at $5000 \mathrm{~m})$, consistent with Ricaud et al. (2014c). The diurnal cycle in temperature anomaly of $\pm 5 \mathrm{~K}$ amplitude is observed in summer and, with a lesser amplitude $( \pm 2 \mathrm{~K})$, in autumn/spring within the lowermost troposphere at $10 \mathrm{~m}$ (Fig. 1), as already shown in Ricaud et al. (2012). The day-to-day variability, particularly visible in winter because of the lack of solar radiation, is also much greater in the lowermost troposphere $( \pm 10 \mathrm{~K})$ than in the entire free troposphere ( $\pm 5 \mathrm{~K}$ at $125 \mathrm{~m}$ down to $\pm 2 \mathrm{~K}$ at $5000 \mathrm{~m}$ ). During the first days of 2014 (1-3 January), the temperature anomaly was unusually high from the PBL to the middle free troposphere: $+30 \mathrm{~K}$ at $10 \mathrm{~m}$ compared to a maximum of $+20 \mathrm{~K}$ in other years, $+20 \mathrm{~K}$ at $125 \mathrm{~m}$ compared to a maximum of $+10-15 \mathrm{~K}$ in other years, and $+25 \mathrm{~K}$ at $1000 \mathrm{~m}$ compared to a maximum of $+10 \mathrm{~K}$ in other years. At $5000 \mathrm{~m}$, the HAMSTRAD temperature anomaly appears to be noisy over this 3-day period, with an average maximum amplitude of $+5 \mathrm{~K}$ compared to $+10 \mathrm{~K}$ in the radiosondes, but only slightly greater than the temperature anomaly of other years $(\sim+5 \mathrm{~K})$. This 3-day period was associated with an unusual massive injection of wet and warm air masses from oceanic origins that generated thick clouds (data not shown), high humidity and high temperature in the entire troposphere including the PBL and the free troposphere.

If we now consider the yearly-averaged biases between HAMSTRAD and the radiosonde temperatures (Fig. 5), they range from -2 to $+6 \mathrm{~K}$ in the PBL $(0-200 \mathrm{~m})$, from -1.5 to $+0.5 \mathrm{~K}$ in the lowermost troposphere $(200-1000 \mathrm{~m})$, from -10 to $0 \mathrm{~K}$ in the middle troposphere $(1-5 \mathrm{~km})$ and from -2 to $+25 \mathrm{~K}$ in the upper tropospherelower stratosphere $(5-10 \mathrm{~km})$. Further details on the greatest differences observed from year to year are discussed here. Firstly, in the PBL (Fig. 5, right), there is a large difference in the vertical distribution of the yearlyaveraged biases according to the year considered, with, at the surface, a positive bias of $1-6 \mathrm{~K}$ in $2009-12$, and a negative bias of $-1.5 \mathrm{~K}$ in 2013 and 2014. Furthermore, there is a systematic local maximum of $\sim 80 \mathrm{~m}$ in 2009-12, that is absent in the 2013-14 yearly-averaged biases. This obviously traces, in the $0-80 \mathrm{~m}$ domain, the impact of the new acquisition software (version V8.31), including also the new retrieval method, that was implemented on 13 January 2013 (Table I). This new version of the software should provide more precise temperature and water vapour vertical profiles in the PBL since there are more scanning angles at low elevations to retrieve temperature and absolute humidity data using a quadratic instead of a linear regression method. Secondly, in the free troposphere $(1-5 \mathrm{~km})$, the negative yearly-averaged biases tend to increase from 2009 (-1 K) to 2014 (-9 K). We note that the biases are, in absolute, greater in 2013 (V8.31) and in 2014 (V8.46) than in 2009-12 (V7.51). Thirdly, although it is known that the instrument loses sensitivity in the upper troposphere-lower stratosphere (Ricaud et al. 2013, 2014c), namely the retrievals are strongly impacted by the information injected in the linear or quadratic regression method, there are large differences in the yearly-averaged biases according to the year considered: $\sim-2 \mathrm{~K}$ in $2012,+5 \mathrm{~K}$ in $2011,+10 \mathrm{~K}$ in $2010,+12 \mathrm{~K}$ in 


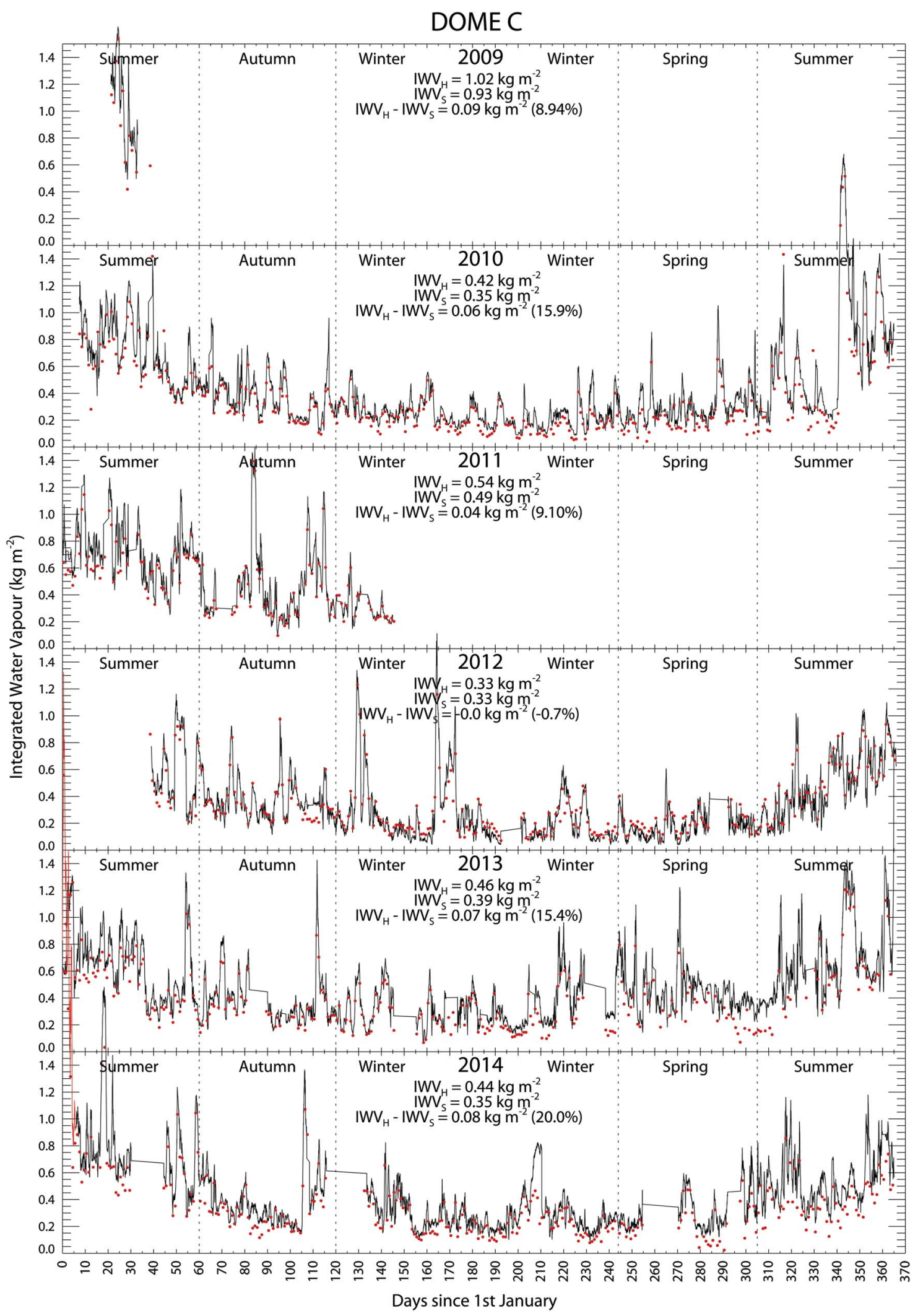

Fig. 7. Time series from 2009 to 2014 (top to bottom) of IWV $\left(\mathrm{kg} \mathrm{m}^{-2}\right)$ as measured by HAMSTRAD (black line) and the radiosondes (red dots). The yearly-averaged IWV $\left(\mathrm{kg} \mathrm{m}^{-2}\right)$ from HAMSTRAD $\left(\mathrm{IWV}_{\mathrm{H}}\right)$ and from the radiosondes $\left(\mathrm{IWV}_{\mathrm{S}}\right)$ and the difference $\left(I W V_{H}-I_{W}\right)$ are highlighted in each panel, together with the relative difference (\%). In 2010, together with the HAMSTRAD measurements, four radiosonde IWV are shown outside of the scale, the values are: $2.09,1.65,1.93$ and $2.02 \mathrm{~kg} \mathrm{~m}^{-2}$ on 7 February, 8, 9 and 10 December 2010, respectively. In 2014, together with the HAMSTRAD measurements, three radiosonde IWV are shown outside of the scale, the values are: $3.55,2.45$ and $1.82 \mathrm{~kg} \mathrm{~m}^{-2}$ on 1, 2 and 3 January 2014, respectively (red line). 
Table III. Absolute and relative yearly-averaged biases together with the correlation coefficient $(r)$ of HAMSTRAD versus radiosonde IWV measurements from 2009 to 2014.

\begin{tabular}{cccc}
\hline Year & Absolute bias $\left(\mathrm{kg} \mathrm{m}^{-2}\right)$ & Relative bias (\%) & Correlation (r) \\
\hline 2009 & 0.091 & 8.9 & 0.99 \\
2010 & 0.067 & 15.9 & 0.98 \\
2011 & 0.049 & 9.1 & 0.99 \\
2012 & -0.002 & -0.7 & 0.97 \\
2013 & 0.072 & 15.5 & 0.98 \\
2014 & 0.089 & 20.0 & 0.98 \\
\hline
\end{tabular}

$2009,+13 \mathrm{~K}$ in 2013 and $+25 \mathrm{~K}$ in 2014 at $7 \mathrm{~km}$. Note that for 2013 (V8.31) and 2014 (V8.46) the estimated biases are the worst. Finally, regardless of the altitude considered, the greatest differences in the biases obtained with the same acquisition version (V7.51) in 2009 and in 2012 suggest that they are probably induced by the impact of the manual liquid nitrogen calibration that is performed once or twice a year during the summer and winter.

The $1-\sigma$ root mean square (RMS) error on the 7-min integration time HAMSTRAD temperature is $0.25 \mathrm{~K}$ in the PBL, $0.5 \mathrm{~K}$ in the free troposphere and $1 \mathrm{~K}$ in the upper troposphere-lower stratosphere (Ricaud et al. 2013). Even considering short periods, such as for the summer in 2009 or winter in 2011, the error on the yearlyaveraged mean is less than $\sim 0.1 \mathrm{~K}$, namely much less than the calculated biases. Consequently, the yearly-averaged biases in temperature can be considered as significant regardless of the year and the level considered. Note that there is also a seasonal variation of the bias in temperature between HAMSTRAD and the radiosonde data of $\pm 2 \mathrm{~K}$ maximum (not shown) with a bias greater in winter than in summer. Finally, when considering the yearly-averaged biases of HAMSTRAD data in time coincidence within a \pm 20 min window, with radiosonde data, no significant changes were found.

Now consider the vertical distribution of the correlation coefficient $(r)$ between HAMSTRAD and the radiosonde temperature measurements (Fig. 6). Note that, on average, the temporal evolution of temperature as measured by HAMSTRAD is very consistent with the one measured by the radiosonde $(r>0.8)$ both in the PBL and in the free troposphere (below $6 \mathrm{~km}$ ) for all years. The correlation degrades in the upper troposphere-lower stratosphere (above $6 \mathrm{~km}$ ) in 2009 ( $r$ ranging from -0.2 to +0.5 ) and 2014 ( $r$ ranging from +0.4 to +0.8 ). Firstly, in the PBL (Fig. 6, right), the correlation is extremely high $(r>0.97)$ for most years, it is slightly less in $2009(r \sim 0.95)$ and $2012(r \sim 0.85)$. In 2009, the data sampling was limited to only 12 days. However, in 2012, there is a good coverage of HAMSTRAD and radiosonde measurements for the whole year. Thus, the reduced correlation rate in 2012 cannot be related to a sampling issue. Secondly, in the free troposphere $(1-5 \mathrm{~km})$, the correlation is high $(r>0.90)$ for all years except $2012(r \sim 0.7-0.8)$ and 2009 ( $r$ ranges from $\sim 0.95$ to 0.2 ). Thirdly, in the upper troposphere-lower stratosphere, the correlation is again high $(r>0.90)$ for all years except 2009 ( $r$ ranges from +0.2 to -0.2 ) and 2014 ( $r$ ranges from +0.8 to +0.4 ).

In general, irrespective of the altitude considered, the lowest correlation coefficients obtained in 2009 can be explained by the lowest statistics since only 12 days are taken into account. For 2012 and 2014, explaining why the correlation coefficients are the lowest in the whole troposphere and in the upper troposphere-lower stratosphere, respectively, is more challenging and cannot be explained by a straightforward link to the change in acquisition software and/or to the impact of the liquid nitrogen calibration on the calibrated spectra.

\section{Integrated water vapour}

Figure 7 shows the IWV time series (2009-14) as measured by HAMSTRAD and the radiosondes. The yearly-averaged absolute and relative biases between HAMSTRAD and the radiosondes are shown in Table III for 2009-14, together with the correlation coefficients $(r)$ between HAMSTRAD and the radiosondes.

First, note the seasonal variations in IWV with maxima in summer (averaging $0.6-1.5 \mathrm{~kg} \mathrm{~m}^{-2}$ ) and minima in winter (averaging $0.1-1.0 \mathrm{~kg} \mathrm{~m}^{-2}$ ), consistent with the analyses presented in Tremblin et al. (2011) and Ricaud et al. (2014c).

Table IV. Seasonally-averaged HAMSTRAD IWV $\left(\mathrm{kg} \mathrm{m}^{-2}\right)$ and associated error on the seasonal mean together with the bias $\left(\mathrm{kg}^{-2}\right)$ between HAMSTRAD and the radiosonde IWV measurements from 2009 to 2014 in time coincidence within a temporal window of \pm 20 min. Note there are only summer data for 2009 .

\begin{tabular}{|c|c|c|c|c|c|c|c|c|}
\hline \multirow[b]{2}{*}{ Year } & \multicolumn{2}{|c|}{ Summer } & \multicolumn{2}{|c|}{ Autumn } & \multicolumn{2}{|c|}{ Winter } & \multicolumn{2}{|c|}{ Spring } \\
\hline & IWV & Bias & IWV & Bias & IWV & Bias & IWV & Bias \\
\hline 2009 & $1.012 \pm 0.006$ & 0.090 & N.A. & N.A. & N.A. & N.A. & N.A. & N.A. \\
\hline 2011 & $0.717 \pm 0.003$ & 0.088 & $0.473 \pm 0.003$ & 0.029 & $0.314 \pm 0.005$ & 0.009 & N.A. & N.A. \\
\hline 2012 & $0.525 \pm 0.002$ & 0.010 & $0.376 \pm 0.003$ & 0.012 & $0.259 \pm 0.002$ & -0.007 & $0.168 \pm 0.003$ & -0.041 \\
\hline 2013 & $0.678 \pm 0.002$ & 0.105 & $0.399 \pm 0.003$ & 0.050 & $0.322 \pm 0.002$ & 0.054 & $0.480 \pm 0.003$ & 0.131 \\
\hline 2014 & $0.723 \pm 0.002$ & 0.151 & $0.387 \pm 0.003$ & 0.076 & $0.300 \pm 0.002$ & 0.071 & $0.306 \pm 0.003$ & 0.096 \\
\hline
\end{tabular}

N.A. $=$ not available. 


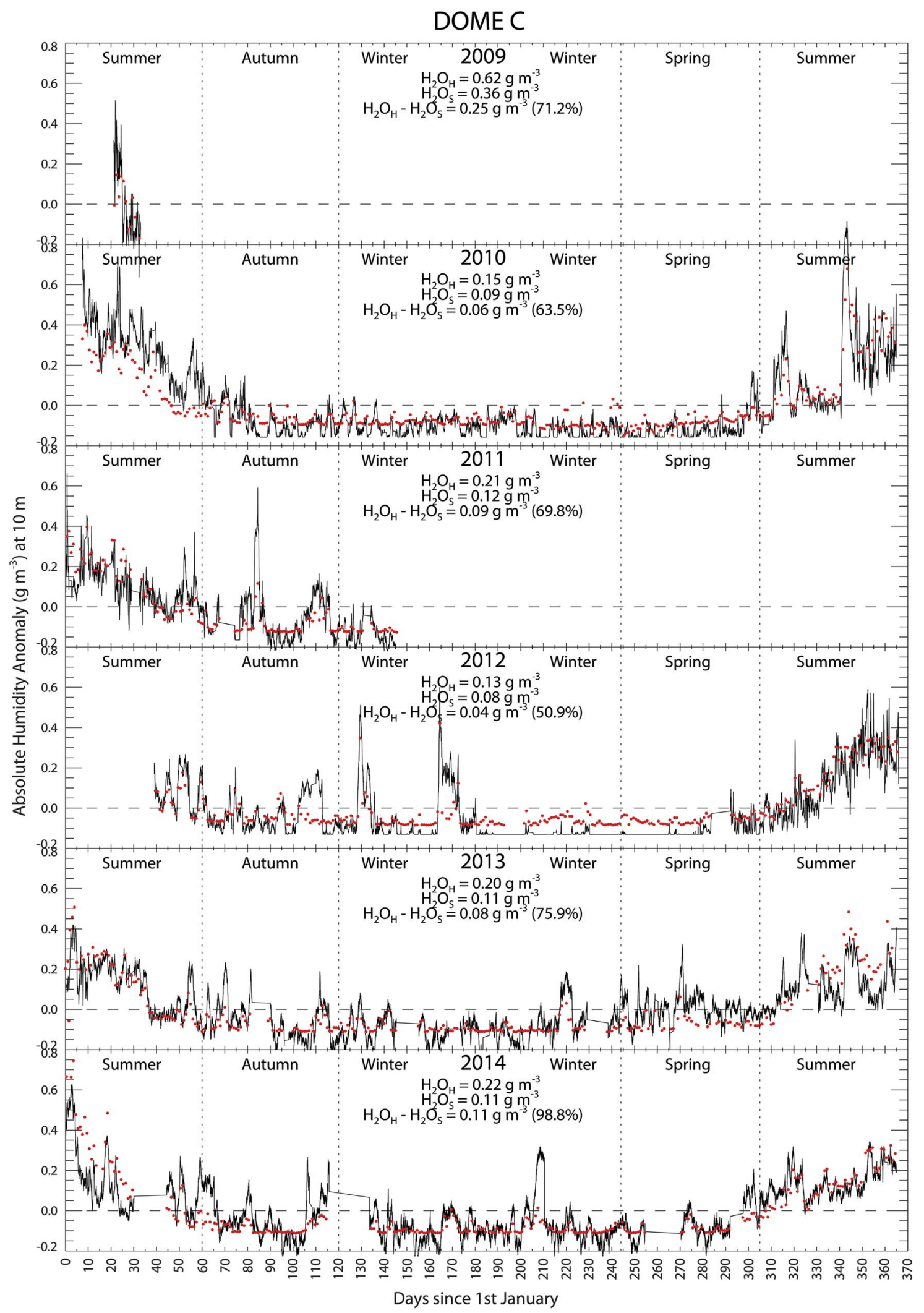

Fig. 8. Time series from 2009 to 2014 (top to bottom) of the absolute humidity anomaly ( $\mathrm{g} \mathrm{m}^{-3}$ ) at $10 \mathrm{~m}$ as measured by HAMSTRAD (black line) and the radiosondes (red dots). The yearly-averaged absolute humidity ( $\mathrm{g} \mathrm{m}^{-3}$ ) from HAMSTRAD $\left(\mathrm{H}_{2} \mathrm{O}_{\mathrm{H}}\right)$ and from the radiosondes $\left(\mathrm{H}_{2} \mathrm{O}_{\mathrm{S}}\right)$ and the difference $\left(\mathrm{H}_{2} \mathrm{O}_{\mathrm{H}}-\mathrm{H}_{2} \mathrm{O}_{\mathrm{S}}\right)$ are highlighted in each panel, together with the relative difference $(\%)$. 
DOME C

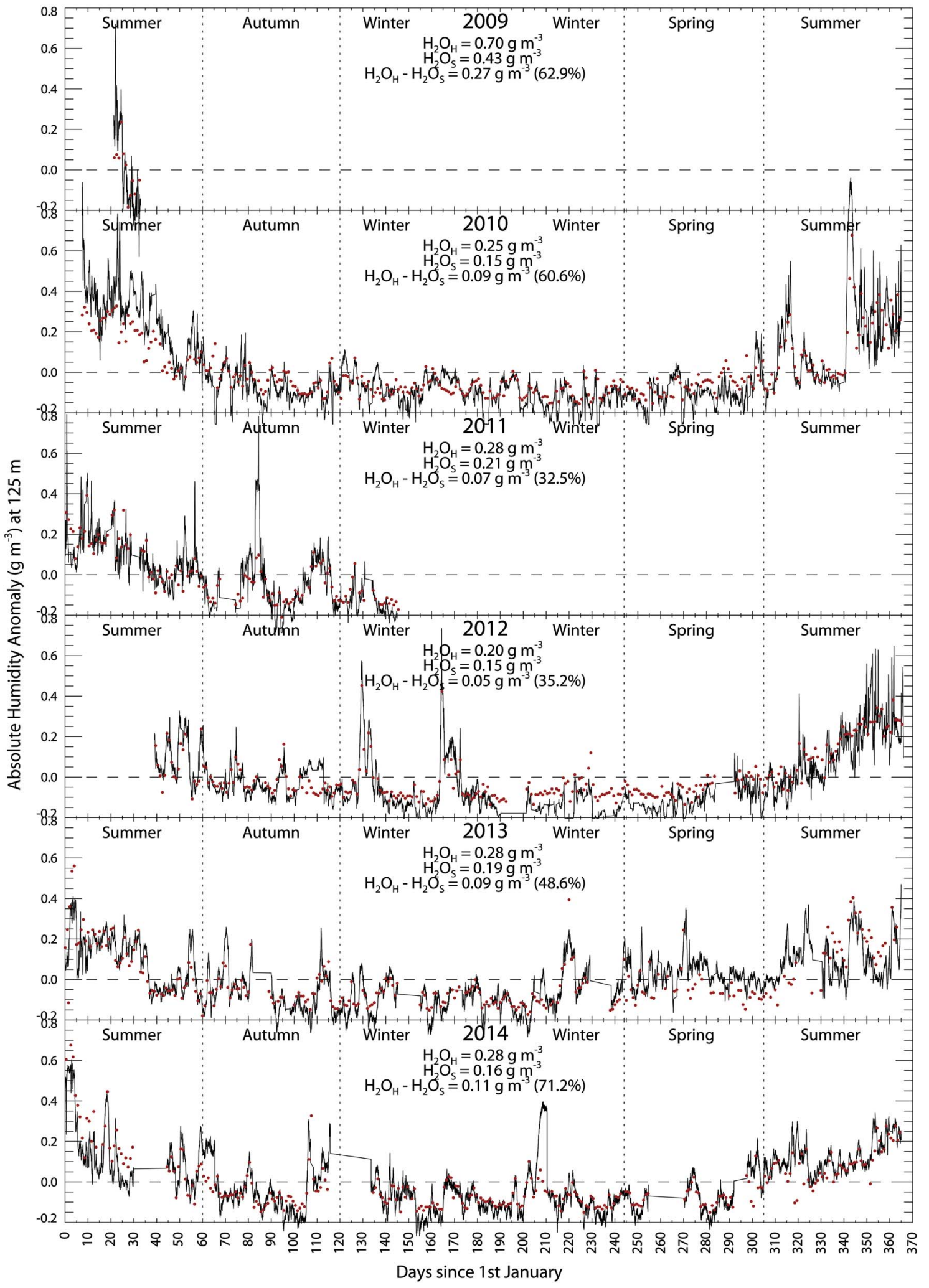

Fig. 9. Time series from 2009 to 2014 (top to bottom) of the absolute humidity anomaly $\left(\mathrm{g} \mathrm{m}^{-3}\right.$ ) at $125 \mathrm{~m}$ as measured by HAMSTRAD (black line) and the radiosondes (red dots). The yearly-averaged absolute humidity $\left(\mathrm{g} \mathrm{m}^{-3}\right)$ from HAMSTRAD $\left(\mathrm{H}_{2} \mathrm{O}_{\mathrm{H}}\right)$ and from the radiosondes $\left(\mathrm{H}_{2} \mathrm{O}_{\mathrm{S}}\right)$ and the difference $\left(\mathrm{H}_{2} \mathrm{O}_{\mathrm{H}}-\mathrm{H}_{2} \mathrm{O}_{\mathrm{S}}\right)$ are highlighted in each panel, together with the relative difference $(\%)$. 
DOME C

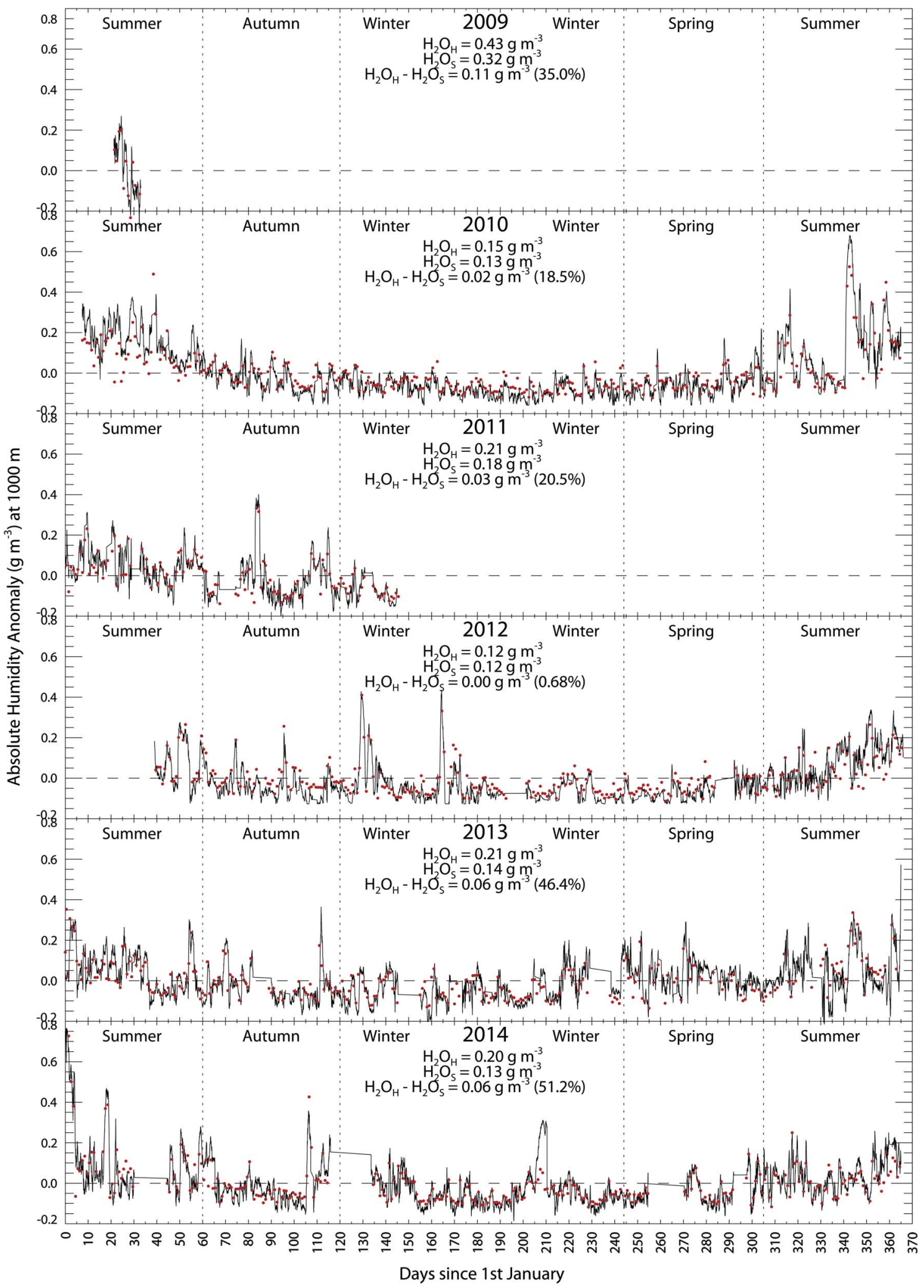

Fig. 10. Time series from 2009 to 2014 (top to bottom) of the absolute humidity anomaly ( $\mathrm{g} \mathrm{m}^{-3}$ ) at $1000 \mathrm{~m}$ as measured by HAMSTRAD (black line) and the radiosondes (red dots). The yearly-averaged absolute humidity ( $\mathrm{g} \mathrm{m}^{-3}$ ) from HAMSTRAD $\left(\mathrm{H}_{2} \mathrm{O}_{\mathrm{H}}\right)$ and from the radiosondes $\left(\mathrm{H}_{2} \mathrm{O}_{\mathrm{S}}\right)$ and the difference $\left(\mathrm{H}_{2} \mathrm{O}_{\mathrm{H}}-\mathrm{H}_{2} \mathrm{O}_{\mathrm{S}}\right)$ are highlighted in each panel, together with the relative difference $(\%)$. 

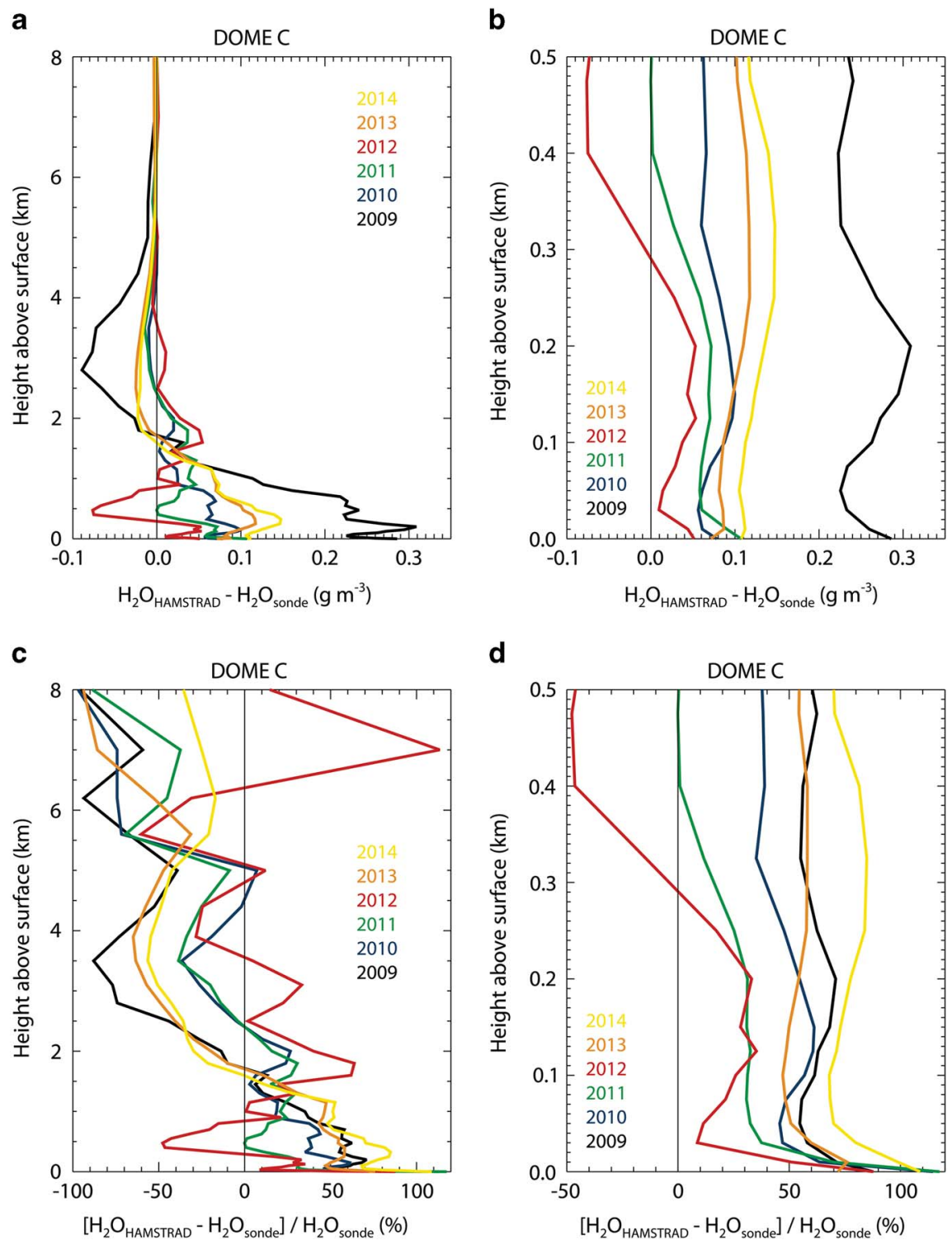

d

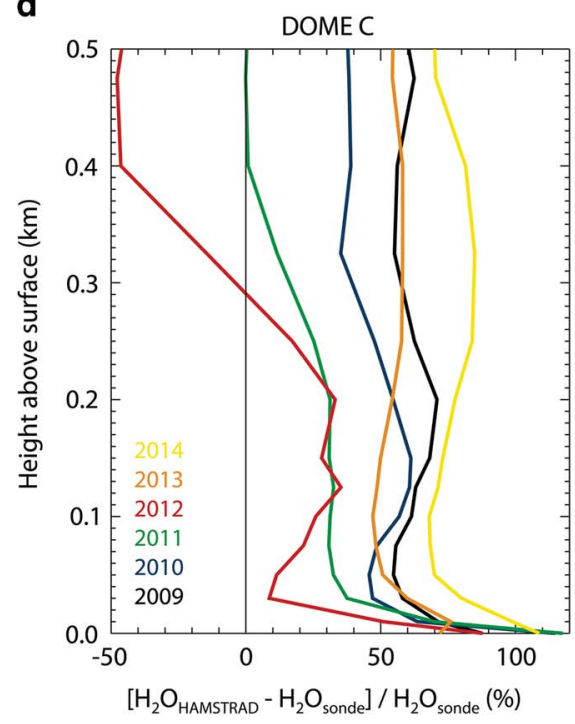

Fig. 11a. \& b. Vertical distribution of the yearly-averaged biases $\left(\mathrm{g} \mathrm{cm}^{-3}\right)$ and c. $\&$ d. relative yearly-averaged biases (\%) in absolute humidity for HAMSTRAD versus radiosondes in 2009 (black line), 2010 (blue line), 2011 (green line), 2012 (red line), 2013 (orange line) and 2014 (yellow line) over the vertical ranges: a. \& c. $0-8 \mathrm{~km}$ and b. \& d. $0-500 \mathrm{~m}$.
On one hand, the maxima in IWV measured consistently by HAMSTRAD and the radiosondes observed: i) on 1-3 January 2014 (values exceeding $3.0 \mathrm{~kg} \mathrm{~m}^{-2}$, exceptional for the Dome $\mathrm{C}$ site) are well correlated with the maxima in temperature from the PBL to the free troposphere, ii) on $8-10$ December 2010 (values exceeding $2.0 \mathrm{~kg} \mathrm{~m}^{-2}$ ) correlate with the maxima in temperature (see Figs 1-3) in the PBL and the free troposphere, and iii) in winter 2012 (e.g. around days 130 and 165 with values exceeding $1.0 \mathrm{~kg}$ $\mathrm{m}^{-2}$ ) are well correlated with the maxima in temperature in the PBL and the free troposphere (Figs 1-3). On the other hand, the minima in IWV measured by the radiosondes in October 2010, 2013 and 2014 (values ranging from 0.05 to $0.1 \mathrm{~kg} \mathrm{~m}^{-2}$ ) are much less than HAMSTRAD IWV by $0.1 \mathrm{~kg} \mathrm{~m}^{-2}$.

In general, the atmosphere as measured by HAMSTRAD is slightly wetter than the atmosphere as measured by the radiosondes, except for 2012. Indeed, for all years except 2012, the yearly-averaged biases between HAMSTRAD and the radiosondes (Table III) range from 0.049 to $0.091 \mathrm{~kg} \mathrm{~m}^{-2}(8.9-20.0 \%)$. While in 2012 the yearly-averaged bias is almost null, namely $-0.002 \mathrm{~kg} \mathrm{~m}^{-2}$ $(-0.71 \%)$. Note that the yearly-averaged biases degrade from 2012 to 2014 from $-0.71 \%$ to $20.0 \%$, respectively. The correlation coefficients $(r)$ between HAMSTRAD and the radiosondes are extremely high, ranging from 0.97 to 0.99 , over 2009-14. Although a dry bias in the radiosondes of a few percent has previously been noted (Rowe et al. 2008, Tomasi et al. 2011, 2012, Ricaud et al. 2013) consistent with the current analysis, both the radiosondes and HAMSTRAD track the same temporal evolution of IWV from 2009 to 2014.

Now consider the seasonal evolution of the bias between HAMSTRAD and the radiosondes (Table IV). 

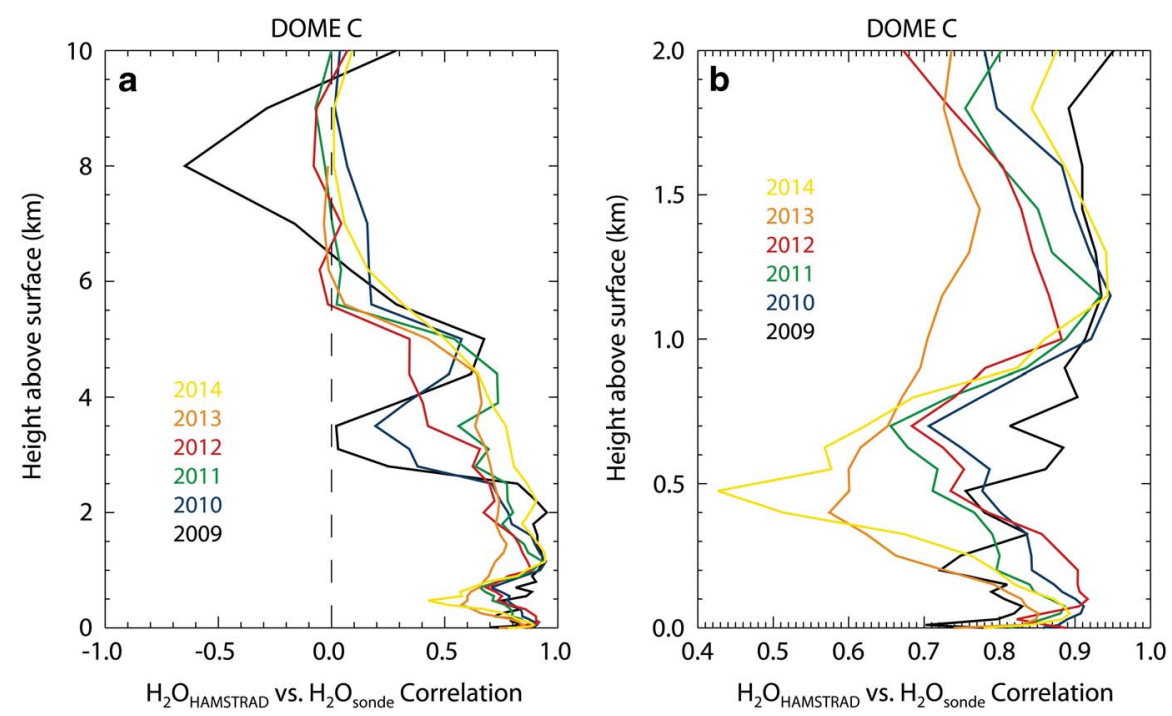

Fig. 12. Vertical distribution of the correlation coefficient between the time evolution of absolute humidity as measured by HAMSTRAD and radiosondes in 2009 (black line), 2010 (blue line), 2011 (green line), 2012 (red line), 2013 (orange line) and 2014 (yellow line) over the vertical ranges: a. $0-10 \mathrm{~km}$ and b. $0-2 \mathrm{~km}$.
The error associated to the HAMSTRAD seasonallyaveraged IWV is always less than the seasonally-averaged bias whatever the season and year considered, even during periods of low numbers of measurements such as in the summer of 2009 and the winter of 2011. Thus, we conclude that there is a significant bias in IWV between HAMSTRAD and the radiosondes. Remember that the 1- $\sigma$ RMS error on the 7-min integration time HAMSTRAD IWV is $0.05 \mathrm{~kg} \mathrm{~m}^{-2}$ or $\sim 5 \%$ (Ricaud et al. 2013). In general, the summer bias $\left(\sim 0.1 \mathrm{~kg} \mathrm{~m}^{-2}\right)$ is on average twice that of the winter bias $\left(\sim 0.05 \mathrm{~kg} \mathrm{~m}^{-2}\right)$ mainly because IWV is twice as great in summer $\left(\sim 0.6-0.7 \mathrm{~kg} \mathrm{~m}^{-2}\right)$ as in winter $\left(0.3 \mathrm{~kg} \mathrm{~m}^{-2}\right)$. As with temperature, when considering the yearly-averaged biases of HAMSTRAD IWV data in time coincidence within a \pm 20 min window with radiosonde data, no significant changes were found.

\section{Tropospheric absolute humidity}

The time evolution of the absolute humidity anomaly (difference between absolute humidity and the yearlyaveraged absolute humidity) as measured by HAMSTRAD and by the radiosondes at $10 \mathrm{~m}(\mathrm{PBL})$ is shown in Fig. 8 for 2009-14. The same evolution is shown in Figs 9 and 10 for the absolute humidity anomaly at $125 \mathrm{~m}$ (middle/upper PBL in summer and low free troposphere in the other seasons), and at $1000 \mathrm{~m}$ (free troposphere), respectively. The yearly-averaged biases along the vertical $(0-10 \mathrm{~km}$ above the ground) between HAMSTRAD and the radiosondes are shown in Fig. 11 for 2009-14. The correlation coefficients $(r)$ along the vertical between HAMSTRAD and the radiosondes are shown in Fig. 12 for 2009-14. Note that, in contrast to what has been shown for temperature, we do not provide any time series for absolute humidity in the upper troposphere-lower stratosphere (e.g. at $5000 \mathrm{~m}$ ) due to a lack of sensitivity of HAMSTRAD in absolute humidity measurements (see Ricaud et al. 2014c).

As mentioned in the previous section regarding IWV and in the absolute humidity study in 2010 by Ricaud et al. (2014c), the seasonal variation of absolute humidity exhibits maxima in summer and minima in winter for all years considered 2010-14 with an amplitude larger in the lowermost troposphere $\left(+0.4\right.$ to $-0.2 \mathrm{~g} \mathrm{~m}^{-3}$ at 10 and $125 \mathrm{~m})$ than in the free troposphere $\left( \pm 0.2 \mathrm{~g} \mathrm{~m}^{-3}\right.$ at $1000 \mathrm{~m}$ ). Unlike with temperature, the diurnal cycle in absolute humidity is not obviously detected in summer since its amplitude is much weaker than the temperature diurnal amplitude (Ricaud et al. 2012). Nevertheless, in the first few days of 2014 (1-3 January), the absolute humidity anomaly was unusually high from the PBL to the middle free troposphere: $+0.8 \mathrm{~g} \mathrm{~m}^{-3}$ at 10,125 and $1000 \mathrm{~m}$ compared to a maximum of $+0.4 \mathrm{~g} \mathrm{~m}^{-3}$ other years. Note a huge increase in absolute humidity at the beginning of December 2010 reaching, within 3 days, $0.8 \mathrm{~g} \mathrm{~m}^{-3}$ at $10 \mathrm{~m}$ and $125 \mathrm{~m}$, and $0.6 \mathrm{~g} \mathrm{~m}^{-3}$ at $1000 \mathrm{~m}$, that is associated with an increase in temperature (Figs 1-3) of $\sim 10 \mathrm{~K}$ at 10,125 and $1000 \mathrm{~m}$. Using 5-day backtrajectories, Ricaud et al. (2013) attribute these episodes of high temperature and high absolute humidity over Dome $\mathrm{C}$ to air masses originating from oceanic wet and warm areas. Conversely, dry and cold periods over Dome $\mathrm{C}$ are obviously in phase with air masses originating from the cold and dry Antarctic continent. Also note the plateau observed over the winter in the HAMSTRAD absolute humidity at $10 \mathrm{~m}$ in 2010 and 2012 that is linked to the minimum values set to zero in these periods, induced by the acquisition and retrieval software V7.51 (Table I). 
If we now quantify the yearly-averaged absolute and relative biases between HAMSTRAD and the radiosonde absolute humidity (Fig. 11), they range from -0.1 to $+0.3 \mathrm{~g} \mathrm{~m}^{-3}$ (from 0 to $+100 \%$ ) in the PBL $(0-200 \mathrm{~m}$ ), -0.1 to $+0.3 \mathrm{~g} \mathrm{~m}^{-3}$ (from $-50 \%$ to $+75 \%$ ) in the lowermost troposphere $\left(200-1000 \mathrm{~m}\right.$ ), and -0.1 to $0.1 \mathrm{~g} \mathrm{~m}^{-3}$ (from $-100 \%$ to $+50 \%)$ in the middle troposphere $(1-4 \mathrm{~km})$. Note that above $4 \mathrm{~km}$ both the sensitivity of the HAMSTRAD instrument and the amount of absolute humidity dramatically decrease; thus, biases in the domain $4-10 \mathrm{~km}$ will not be discussed. There are lots of differences from year to year in the vertical distribution of the biases but the general trend is that the atmosphere is much wetter in the HAMSTRAD measurements compared to the radiosondes below $1.5-2 \mathrm{~km}$ and much drier above. If we exclude the data from the poorlysampled 2009, we observe that, in the PBL, biases are all positive within $0-0.1 \mathrm{~g} \mathrm{~m}^{-3}(0-100 \%)$ with the smallest bias in 2012 and the greatest bias in 2014. The impact of the acquisition software on to the biases in the PBL is not obvious. That is not the case in the free troposphere $(0.2-4 \mathrm{~km})$ where the biases in 2013 and 2014 behave consistently (versions V8.31 and V8.46, respectively) from +0.12 to $-0.02 \mathrm{~g} \mathrm{~m}^{-3}$ (from $-75 \%$ to $+75 \%$ ), whilst the biases in 2010 and 2011 behave consistently (version V7.51) from +0.05 to $-0.01 \mathrm{~g} \mathrm{~m}^{-3}$ (from $+30 \%$ to $-40 \%$ ). As with temperature, regardless of the altitude considered, the biases obtained in 2012 compared to 2010 and 2011 with the same acquisition version (V7.51) are very different with a minimum at $0.5 \mathrm{~km}$ of $-0.08 \mathrm{~g} \mathrm{~m}^{-3}$ $(-50 \%)$ and a maximum of $+0.05 \mathrm{~g} \mathrm{~m}^{-3}(+60 \%)$ at $1.5 \mathrm{~km}$. The atypical bias in 2012 suggests that the manual liquid nitrogen calibration performed once or twice a year during the summer and winter has an impact on the HAMSTRAD measurements. Finally, note that the new acquisition software has not reduced the biases in absolute humidity between HAMSTRAD and the radiosondes in either the PBL or the free troposphere.

The 1- $\sigma$ RMS error on the 7-min integration time HAMSTRAD absolute humidity is $0.05 \mathrm{~g} \mathrm{~m}^{-3}(10 \%)$ in the PBL, $0.03 \mathrm{~g} \mathrm{~m}^{-3}(10-15 \%)$ in the free troposphere and $0.005 \mathrm{~g} \mathrm{~m}^{-3}(15 \%)$ in the upper troposphere-lower stratosphere (Ricaud et al. 2013). Even considering short periods, such as in the summer of 2009 or the winter of 2011 , the error on the yearly-averaged mean is less than $\sim 2 \%$, namely much less than the calculated biases. Consequently, the yearly-averaged biases in absolute humidity can be considered as significant irrespective of the year and the level considered below $4 \mathrm{~km}$. Note that there is also a seasonal variation of the bias in absolute humidity between HAMSTRAD and the radiosonde data of $\pm 0.01 \mathrm{~g} \mathrm{~m}^{-3}$ maximum (not shown) with a bias greater in summer than in winter. Finally, as with temperature and IWV, no significant changes were found when considering the yearly-averaged biases of
HAMSTRAD data in time coincidence within a $\pm 20 \mathrm{~min}$ window with the radiosonde data.

If we consider the vertical distribution of the correlation coefficient $(r)$ between HAMSTRAD and the radiosonde measurements of absolute humidity (Fig. 12), we find that, from 0 to $2 \mathrm{~km}$, the temporal evolution of absolute humidity is consistently measured by both techniques $(r>0.7)$ for all the years considered, except for 2013 and 2014 which show a weak correlation coefficient of 0.6 and 0.4 , respectively, at $\sim 0.5 \mathrm{~km}$. From 2 to $4 \mathrm{~km}, r$ slightly decreases from 0.7 to 0.6 for all years considered, except for 2009 and 2010 at $\sim 3.0 \mathrm{~km}$ when a very weak correlation coefficient is calculated to be 0 and 0.2 , respectively. Below $2 \mathrm{~km}$, the vertical distribution of $r$ is very consistent $(r \sim 0.7-1.0)$ for $2009-12$ processed with version V7.51. Above $2 \mathrm{~km}$, the vertical distribution of $r$ is very consistent $(r \sim 0.6-0.8)$ for 2013 (V8.31) and 2014 (V8.46). Finally note that, in contrast to temperature, the vertical distribution of $r$ in 2012 does not significantly differ from other years.

\section{Conclusions}

The HAMSTRAD $\left(\mathrm{H}_{2} \mathrm{O}\right.$ Antarctica Microwave Stratospheric and Tropospheric Radiometers) radiometer is a state-of-the-art microwave radiometer dedicated to the measurement of tropospheric absolute humidity at 169-197 GHz (G-band, strong $\mathrm{H}_{2} \mathrm{O}$ line at $183.3 \mathrm{GHz}$ ), together with tropospheric temperature from the oxygen $\left(\mathrm{O}_{2}\right)$ line $(51-59 \mathrm{GHz}, \mathrm{V}$-band, lower frequency wing of the $\mathrm{O}_{2}$ line), in very cold and dry environments, such as that encountered at Dome $\mathrm{C}$ all year round. The HAMSTRAD radiometer samples the whole 24-h diurnal cycle with a 7-min integration time from 2009 to 2014 , and from 0 to $10 \mathrm{~km}$ above surface, with a vertical resolution from $\sim 30 \mathrm{~m}$ in the PBL to $\sim 500 \mathrm{~m}$ in the upper troposphere-lower stratosphere. Considering the HAMSTRAD measurements in conjunction with other datasets (in situ, radiosondes, satellite, lidar, meteorological analyses, back-trajectories, mesoscale models), we have been able to study different processes in the Antarctic troposphere including: i) diurnal variability of temperature and absolute humidity in the PBL, ii) seasonal variability of temperature and absolute humidity in the PBL and in the free troposphere, iii) temperature versus absolute humidity correlation along the vertical from the lowermost to the middle troposphere and iv) episodes of clouds and diamond dusts above the station.

The measurements of tropospheric temperature and absolute humidity vertical profiles together with IWV provided by the HAMSTRAD radiometer have been reviewed from 2009 to 2014 in comparison with radiosondes launched at $12 \mathrm{~h} 00$ UTC. This exercise 
enlarges the previous study that only concentrated on the 2010 data but encompassed, in addition to radiosondes, in situ and spaceborne measurements, together with meteorological analyses. It is well known that radiosondes have biases at polar latitudes, in particular at Dome $\mathrm{C}$, both in terms of temperature and humidity. Nevertheless, our previous analyses based upon data from 2010 did show some consistency between radiosondes and all of the other datasets versus HAMSTRAD measurements.

We can state the following points regarding the quality of the HAMSTRAD measurements with a 7-min integration time over the period 2009-14, based upon an extensive evaluation of biases and time correlation coefficients $(r)$ along the vertical. i) HAMSTRAD IWV measurements are of excellent quality showing high time correlation with radiosonde data $(r>0.98)$, and can be used without retrieving significant bias. ii) HAMSTRAD temperature measurements are suitable for scientific analyses over the range of $0-10 \mathrm{~km}$ with high time correlation with radiosondes $(r>0.80)$. Nevertheless, the vertical distribution of temperature from 0 to $10 \mathrm{~km}$ is subject to biases that need to be removed if the scientific analyses require the use of vertical profiling. iii) HAMSTRAD absolute humidity measurements are suitable for scientific analyses but all within the range of $0-4 \mathrm{~km}$ with a moderate time correlation with radiosondes $(r>0.70)$. Nevertheless, the vertical distribution of absolute humidity from 0 to $4 \mathrm{~km}$ is subject to biases that need to be removed if the scientific analyses require the use of vertical profiling. Above $4 \mathrm{~km}$, the instrument loses sensitivity and the amount of absolute humidity falls down. Using HAMSTRAD data from 2009 to 2014 we confirm the findings of previous studies from 2009 and 2010.

The whole HAMSTRAD dataset including temperature, absolute humidity and IWV covering 2009-14 with a time resolution of 7 minutes is provided in open access to the scientific community at http://www.cnrm.meteo.fr/spip. php?article961\&lang=en. In addition, the yearly-averaged biases along the vertical for 2009-14 are also provided for scientific studies that consider vertical profiling. By these means, the HAMSTRAD measurements will contribute to the investigation of physical processes above the Dome $\mathrm{C}$ station by combining HAMSTRAD data with other measurements (e.g. aerosol lidar, radiation budget, meteorological parameters, etc.) both short-term, e.g. ice crystal episodes (diamond dust), and long-term, e.g. trends in temperature and absolute humidity, and/or for the validation of satellite data.

\section{Acknowledgements}

The HAMSTRAD programme is funded by the Institut National des Sciences de l'Univers (INSU)/Centre
National de la Recherche Scientifique (CNRS), the Institut polaire français Paul-Emile Victor (IPEV), MétéoFrance and the Centre National d'Etudes Spatiales (CNES). The permanently manned Concordia Station is jointly operated by IPEV and the Italian Programma Nazionale Ricerche in Antartide (PNRA). We would like to thank all the overwinter personnel who have worked at Dome C since 2009 on the two projects: HAMSTRAD and radiosondes. Finally, the two anonymous reviewers are acknowledged for their fruitful comments.

\section{Author contribution statement}

P. Ricaud led the research and contributed $80 \%$ to the data collection, data analysis and preparation of the manuscript. P. Grigioni and R. Zbinden contributed 3\% towards the research. J.-L. Attié, L. Genoni, A. Galeandro, L. Moggio, S. Montaguti, I. Petenko and P. Legovini contributed $2 \%$ towards the data collection.

\section{References}

Aristidi, E., Agabi, A., Vernin, J., Azouit, M., Martin, F., Ziad, A. \& Fossat, E. 2003. Antarctic site testing: first daytime seeing monitoring at Dome C. Astronomy and Astrophysics, 406, 19-22.

Argentini, S., Pietroni, I., Mastrantonio, G., Viola, A. \& Zilitinchevich, S. 2007. Characteristics of the night and day time atmospheric boundary layer at Dome C, Antarctica. EAS Publications Series, 25, 49-55.

Argentini, S., Petenko, I., Viola, A., Mastrantonio, G., Pietroni, I., Casasanta, G., Aristidi, E. \& Genthon, C. 2013. The surface layer observed by a high-resolution sodar at DOME C, Antarctica. Annals of Geophysics, 56, 10.4401/ag-6347.

Aumann, H., Gregorich, D. \& Broberg, S. 2006. AIRS observations of Dome $\mathrm{C}$ in Antarctica and comparison with automated weather stations. Proceedings of the Fifteenth International TOVS Study Conference, 140-147.

De Gregori, S., De Petris, M., Decina, B., Lamagna, L., Pardo, J.R., Petkov, B., Tomasi, C. \& Valenzano, L. 2012. Millimetre and submillimetre atmospheric performance at Dome $\mathrm{C}$ combining radiosoundings and atm synthetic spectra. Monthly Notices of the Royal Astronomical Society, 425, 10.1111/j.1365-2966.2012.21430.x.

Genthon, C., Town, M.S., Six, D., Favier, V., Argentini, S. \& Pellegrini, A. 2010. Meteorological atmospheric boundary layer measurements and ECMWF analyses during summer at Dome C, Antarctica. Journal of Geophysical Research - Atmospheres, 115, 10.1029/2009JD012741.

Hagelin, S., Masciadri, E., Lascaux, F. \& Stoesz, J. 2008. Comparison of the atmosphere above the South Pole, Dome C and Dome A: first attempt. Monthly Notice of the Royal Astronomical Society, 387, 10.1111/j.1365-2966.2008.13361.x.

Hegglin, M.I., Plummer, D.A., Shepherd, T.G., Scinocca, J.F., Anderson, J., Froidevaux, L., Funke, B., Hurst, D., Rozanov, A., Urban, J., von Clarmann, T., Walker, K.A., Wang, H.J., Tegtmeier, S. \& Weigel, K. 2014. Vertical structure of stratospheric water vapour trends derived from merged satellite data. Nature Geoscience, 7, 768-776.

Herbin, H., Hurtmans, D., Clerbaux, C., Clarisse, L. \& Coheur, P.F. 2009. (H2O)-O-16 and HDO measurements with IASI/MetOp. Atmospheric Chemistry and Physics, 9, 9433-9447. 
Hines, K.M., Bromwich, D.H., Rasch, P.J. \& Iacono, M.J. 2004. Antarctic clouds and radiation within the NCAR climate models. Journal of Climate, 17, 10.1175/1520-0442(2004)017.

Miloshevich, L.M., Vömel, H., Whiteman, D.N. \& Leblanc, T. 2009. Accuracy assessment and corrections of Vaisala RS92 radiosonde water vapour measurements. Journal of Geophysical Research Atmospheres, 114, 10.1029/2008JD011565.

Miloshevich, L.M., Vömel, H., Whiteman, D.N., Lesht, B.M., Schmiduin, F.J. \& Russo, F. 2006. Absolute accuracy of water vapour measurements from six operational radiosonde types launched during AWEX-G and implications for AIRS validation. Journal of Geophysical Research - Atmospheres, 111, 10.1029/ 2005JD006083.

Ricaud, P. 2014a. Variabilités de la vapeur d'eau et de la température troposphérique au Dôme C (station Concordia), Antarctique. Partie I: l'instrument HAMSTRAD. La Météorologie, 84, 10.4267/2042/ 53184.

Ricaud, P. 2014b. Variabilités de la vapeur d'eau et de la température troposphérique mesurées par le radiomètre micro-onde HAMSTRAD au Dôme C, Antarctique. Partie II: Résultats scientifiques. La Météorologie, 85, 10.4267/2042/53749.

Ricaud, P., Gabard, B., Derrien, S., Attié, J.-L., Rose, T. \& Czekala, H. 2010a. Validation of tropospheric water vapour as measured by the $183-\mathrm{GHz}$ HAMSTRAD radiometer over the Pyrenees Mountains, France. IEEE Transactions on Geoscience and Remote Sensing, 48, 2189-2203.

Ricaud, P., Gabard, B., Derrien, S., Chaboureau, J.-P., Rose, T., Mombauer, A. \& Czekala, H. 2010b. HAMSTRAD-Tropo, A $183-\mathrm{GHz}$ radiometer dedicated to sound tropospheric water vapor over Concordia Station, Antarctica. IEEE Transactions on Geoscience and Remote Sensing, 48, 10.1109/TGRS.2009.2029345.

Ricaud, P., Carminati, F., Attié, J.-L., Courcoux, Y., Rose, T., Genthon, C., Pellegrini, A., Tremblin, P. \& August, T. 2013. Quality assessment of the first measurements of tropospheric water vapour and temperature by the HAMSTRAD radiometer over Concordia Station, Antarctica. IEEE Transactions on Geoscience and Remote Sensing, 51, 10.1109/TGRS.2012.2225627.

Ricaud, P., Carminati, F., Courcoux, Y., Pellegrini, A., Attié, J.-L., El Amraoui, L., Abida, R., Genthon, C., August, T. \& Warner, J. 2014c. Statistical analyses and correlation between tropospheric temperature and humidity at Dome C, Antarctica. Antarctic Science, 26, 10.1017/S0954102013000564.
Ricaud, P., Genthon, C., Durand, P., Attié, J.-L., Carminati, F., Canut, G., Vanacker, J.-F., Moggio, L., Courcoux, Y., Pellegrini, A. \& RosE, T. 2012. Summer to winter diurnal variabilities of temperature and water vapour in the lowermost troposphere as observed by the HAMSTRAD radiometer over Dome C, Antarctica. Boundary-Layer Meteorology, 143, 10.1007/s10546-011-9673-6.

Rowe, P.M., Miloshevich, L.M., Turner, D.D. \& Walden, V.P. 2008. Dry bias in Vaisala RS90 radiosonde humidity profiles over Antarctica. Journal of Atmospheric and Oceanic Technology, 25, 10.1175/2008JTECHA1009.1.

Scherer, M., Vömel, H., Fueglistaler, S., Oltmans, S.J. \& Staehelin, J. 2008. Trends and variability of midlatitude stratospheric water vapour deduced from the re-evaluated Boulder balloon series and HALOE. Atmospheric Chemistry and Physics, 8, 1391-1402.

Solomon, S., Rosenlof, K.H., Portmann, R.W., Daniel, J.S., Davis, S.M., SAnford, T.J. \& Plattner, G.-K. 2010. Contributions of stratospheric water vapour to decadal changes in the rate of global warming. Science, 327, 1219-1223.

Tobin, D.C., Revercomb, H.E., Knuteson, R.O., Lesht, B.M., Strow, L.L., Hannon, S.E., Feltz, W.F., Moy, L.A., Fetzer, E.J. \& CRESS, T.S. 2006. Atmospheric radiation measurement site atmospheric state best estimates for atmospheric infrared sounder temperature and water vapor retrieval validation. Journal of Geophysical Research - Atmospheres, 111, 10.1029/2005JD006103.

Tomasi, C., Petkov, B.H. \& Benedetti, E. 2012. Annual cycles of pressure, temperature, absolute humidity and precipitable water from the radiosoundings performed at Dome C, Antarctica, over the 20052009 period. Antarctic Science, 24, 10.1017/S0954102012000405.

Tomasi, C., Petkov, B., Benedetti, E., Valenziano, L. \& Vitale, V. 2011. Analysis of a 4 year radiosonde data set at Dome $\mathrm{C}$ for characterizing temperature and moisture conditions of the Antarctic atmosphere. Journal of Geophysical Research - Atmospheres, 116, 10.1029/2011JD015803.

Tremblin, P., Minier, V., Schneider, N., Durand, G.Al., Ashley, M.C.B., Lawrence, J.S., Luong-van, D.M., Storey, J.W.V., Durand, G.AN., Reinert, Y., Veyssiere, C., Walter, C., Ade, P., Calisse, P.G., Challita, Z., Fossat, E., Sabbatini, L., Pellegrini, A., Ricaud, P. \& Urban, J. 2011. Site testing for submillimetre astronomy at Dome C in Antarctica. Astronomy and Astrophysics, 535, 10.1051/00046361/201117345.

Turner, J., Lachlan-Cope, T.A., Colwell, S., Marshall, G.J. \& Connolley, W.M. 2006. Significant warming of the Antarctic winter troposphere. Science, 311, 10.1126/science.1121652. 